Prepared in cooperation with U.S. Fish and Wildlife Service, Fish and Wildlife Office, Portland, Oregon; and Columbia River Fish and Wildlife Conservation Office, Vancouver, Washington

\title{
Evaluating Dewatering Approaches to Protect Larval Pacific Lamprey
}

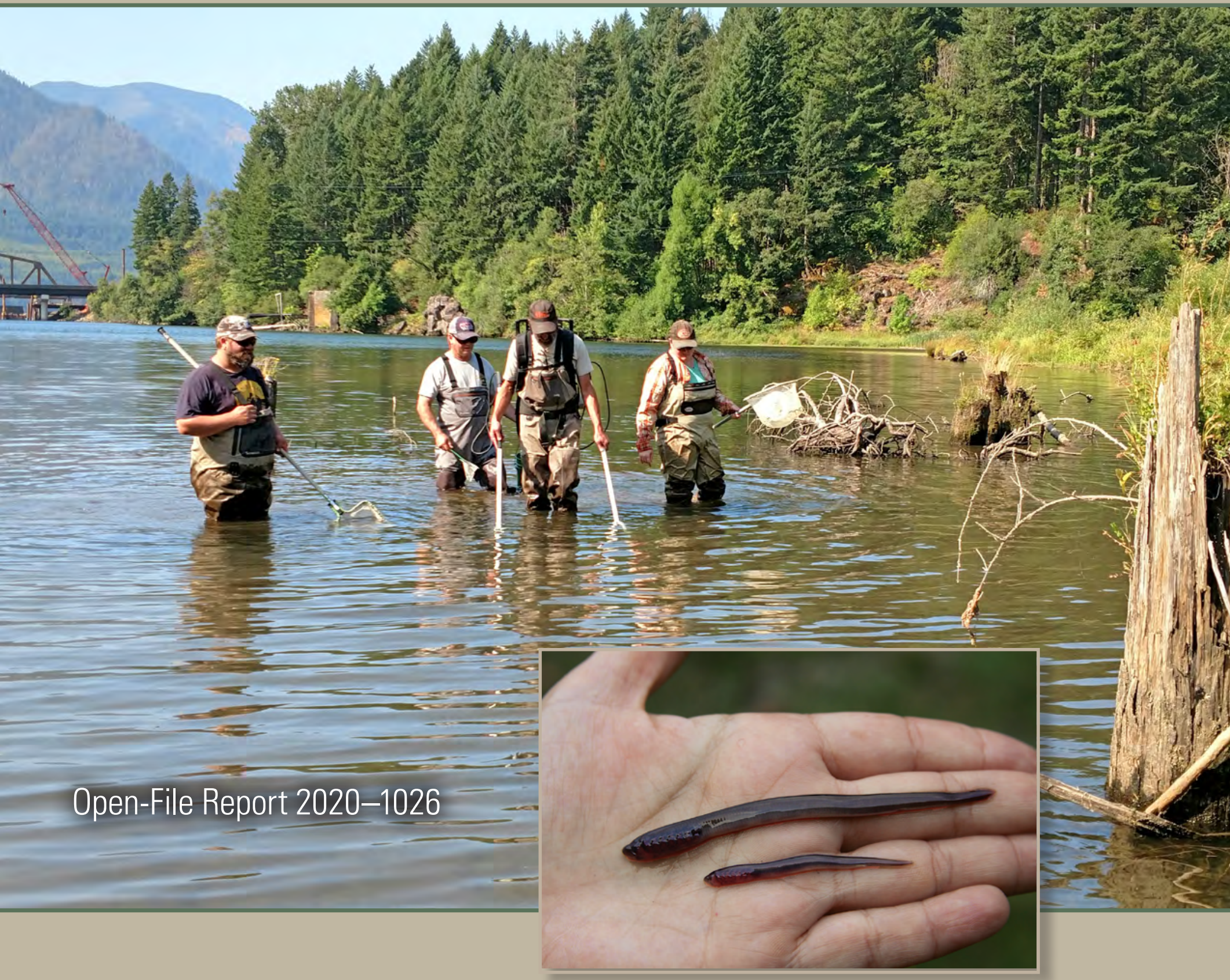

U.S. Department of the Interior

U.S. Geological Survey 
Cover photographs:

Background: Electrofishing for larval lamprey, Wind River, Washington. Inset: Small and large Pacific lamprey larvae shown on hand.

Photographs by Lisa Weiland, U.S. Geological Survey, 2019. 


\section{Evaluating Dewatering Approaches to Protect Larval Pacific Lamprey}

By Theresa L. Liedtke, Lisa K. Weiland, Joseph J. Skalicky, and Ann E. Gray

Prepared in cooperation with U.S. Fish and Wildlife Service, Fish and Wildlife Office, Portland, Oregon; and Columbia River Fish and Wildlife Conservation Office, Vancouver, Washington

Open File Report 2020-1026

U.S. Department of the Interior U.S. Geological Survey 


\title{
U.S. Department of the Interior \\ DAVID BERNHARDT, Secretary
}

\author{
U.S. Geological Survey \\ James F. Reilly II, Director
}

U.S. Geological Survey, Reston, Virginia: 2020

For more information on the USGS—-the Federal source for science about the Earth, its natural and living resources, natural hazards, and the environment-visit https://www.usgs.gov/ or call 1-888-ASK-USGS (1-888-275-8747).

For an overview of USGS information products, including maps, imagery, and publications, visit https://store.usgs.gov/.

Any use of trade, firm, or product names is for descriptive purposes only and does not imply endorsement by the U.S. Government.

Although this information product, for the most part, is in the public domain, it also may contain copyrighted materials as noted in the text. Permission to reproduce copyrighted items must be secured from the copyright owner.

Suggested citation:

Liedtke, T.L., Weiland, L.K., Skalicky. J.J., and Gray, A.E., 2020, Evaluating dewatering approaches to protect larval Pacific lamprey: U.S. Geological Survey Open-File Report 2020-1026, 32 p., https://doi.org/10.3133/ofr20201026.

ISSN 2331-1258 (online) 


\section{Contents}

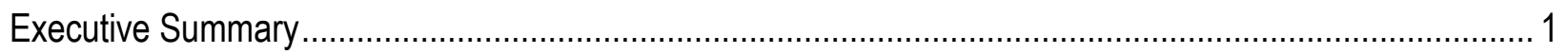

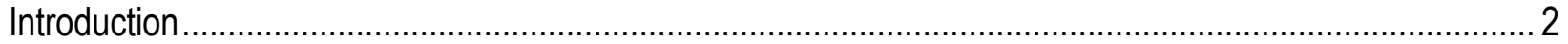

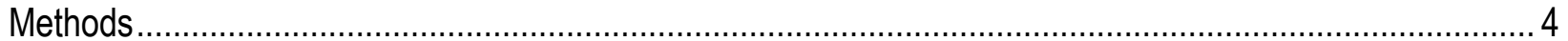

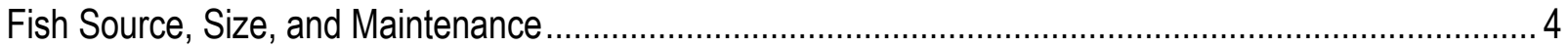

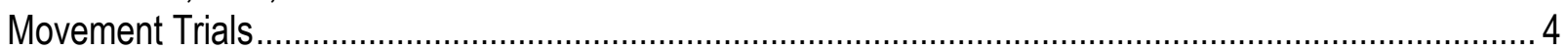

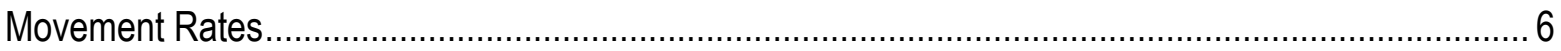

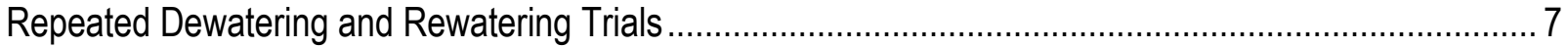
Individual Fish Response .................................................................................................

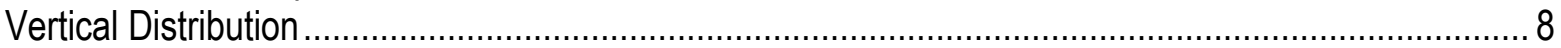

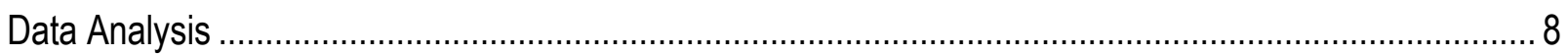

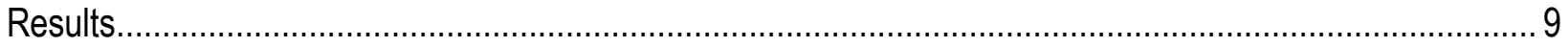

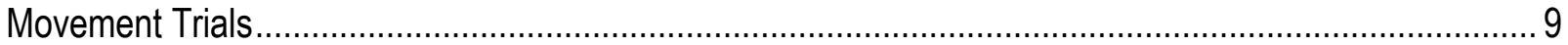

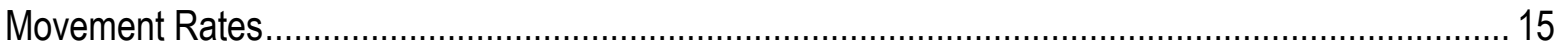

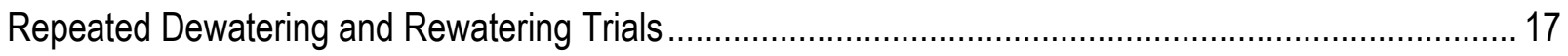

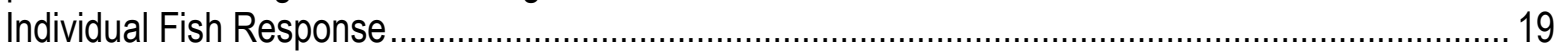

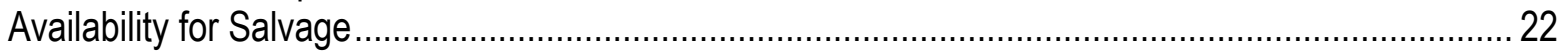

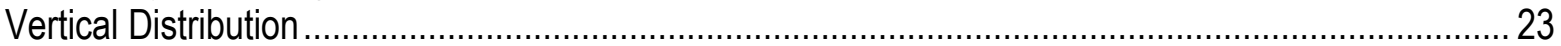

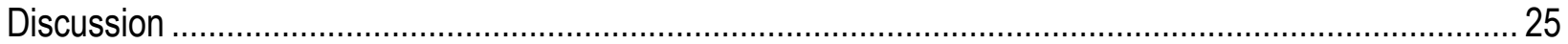

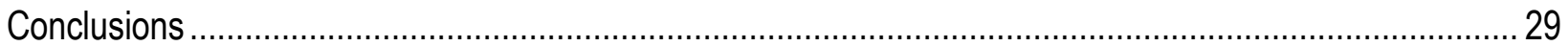

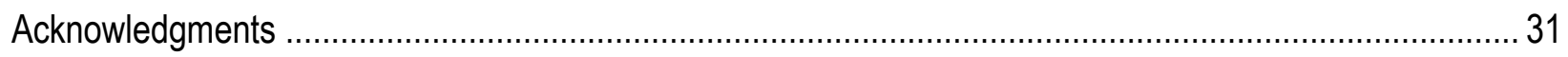

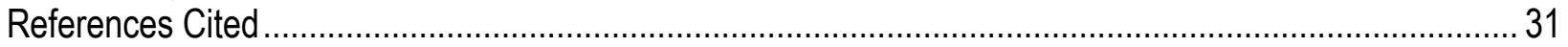

\section{Figures}

Figure 1. Schematic diagram of the tank constructed to evaluate larval lamprey movements in response to dewatering

Figure 2. Distribution of larval lamprey total length in movement trials for dark and light conditions at each of five dewatering rates and for controls

Figure 3. Graph showing percentage of larval lamprey that were stranded or safe at the end of dewatering trials, by group

Figure 4. Graphs showing percentage of larval lamprey in each tank section at the end of movement trials conducted with five dewatering rates under dark and light conditions.

Figure 5. Graphs showing summary of percent emergence and total length for larval lamprey during dewatering trials at five dewatering rates under dark and light conditions

Figure 6. Graph showing median and minimum and maximum time to emerge from sediment for larval lamprey exposed to dewatering at four dewatering rates and dark and light conditions.

Figure 7. Graph showing movement rate for larval lamprey by size category and movement number.......17 Figure 8. Graphs showing the summary of the repeated dewatering and rewatering trials for two dewatering rates and dark and light conditions, by time

Figure 9. Graphs showing individual fish responses and percent emergence for larval lamprey exposed to repeated dewatering and rewatering trials with two dewatering rates and dark and light conditions. 


\section{Tables}

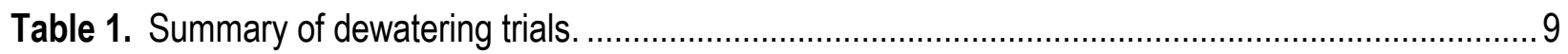

Table 2. Mean time required to reach the test water level in movement trials. ....................................... 10

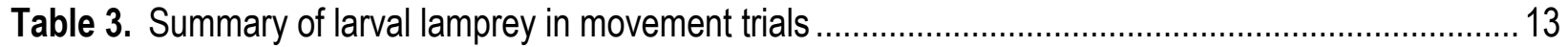

Table 4. Summary of small and large larval lamprey size categories .................................................. 19

Table 5. Vertical distribution of larval lamprey by group and depth strata. .............................................2

Table 6. Vertical distribution of larval lamprey by control and treatment group..........................................2

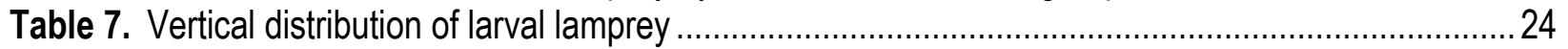

\section{Conversion Factors}

U.S. customary units to International System of Units

\begin{tabular}{|c|c|c|}
\hline Multiply & By & To obtain \\
\hline \multicolumn{3}{|c|}{ Length } \\
\hline inch (in.) & 2.54 & centimeter $(\mathrm{cm})$ \\
\hline foot $(\mathrm{ft})$ & 0.3048 & meter $(\mathrm{m})$ \\
\hline mile (mi) & 1.609 & kilometer $(\mathrm{km})$ \\
\hline
\end{tabular}

International System of Units to U.S. customary units

\begin{tabular}{llll} 
& Multiply & By & To obtain \\
\hline & Length & \\
\hline centimeter $(\mathrm{cm})$. & 2.54 & inch (in.) & \\
\hline
\end{tabular}




\title{
Evaluating Dewatering Approaches to Protect Larval Pacific Lamprey
}

\author{
By Theresa L. Liedtke' ${ }^{1}$ Lisa K. Weiland ${ }^{1}$, Joseph J. Skalicky² ${ }^{2}$ and Ann E. Gray²
}

\section{Executive Summary}

Larval Pacific lamprey live for several years burrowed in nearshore sediments where they filter feed on detritus and organic matter. Dewatering of larval habitat can occur as a result of flow-management practices, construction projects, or seasonal closures of irrigation diversions. Effective management of dewatering events requires guidance on approaches to protect lamprey, such as dewatering rates and light conditions (day or night) that allow lamprey the best opportunity to relocate water and avoid being stranded. We conducted controlled laboratory experiments comparing five dewatering rates $(1,1.8,4,8$, and 16 inches per hour [in/h]) and two light conditions (light and dark) to evaluate their effectiveness in protecting larval lamprey. We used a tank with a simulated shoreline at a 10-percent slope filled with river sediment and manipulated the outflow to control the rate of dewatering until water was covering only the sediment in the lowest tank section, at the bottom of the slope. Following dewatering, larvae were classified as either stranded (in or on the substrate outside the watered area) or safe (relocated to the wetted area at the lower end of the tank). All study groups experienced high rates of stranding. The lowest stranding rates were for $1 \mathrm{in} / \mathrm{h}$, in both light ( 77 percent) and dark ( 80 percent). Faster dewatering rates generally produced higher percentages of stranded fish, and both the dark and light trials at $16 \mathrm{in} / \mathrm{h}$ stranded all larvae. At each of the five dewatering rates, trials conducted in the dark stranded the same or higher proportions of fish than the corresponding trial conducted in the light, so there was no clear advantage to dewatering during dark conditions. The largest contribution to stranding rates for all study groups was the high number of larvae (50-80 percent) that did not initiate movement in response to dewatering and remained in the uppermost tank section where they were stocked at the start of the trials. The proportion of larvae that emerged from the sediment during dewatering trials was approximately 30 percent, and fish that emerged were consistently smaller than those that remained burrowed. Combining all dewatering rates, emergence was 31.3 percent for groups under dark conditions and 30.7 percent for groups under light conditions. We recorded the timing of emergence for 58 larvae and their median time to emerge (after the surface of the sediment in the uppermost tank section was dewatered) was 0.62 hour $(\mathrm{h})($ range $0-4.5 \mathrm{~h}$ ). We measured larval movement rates and found that large fish moved faster than small fish. Differences in larval movement rate based on light condition were significant only for large fish, which had a significantly faster rate during light conditions. Larval lamprey moved, over short distances, at rates that exceeded the fastest dewatering rate we tested. The mean movement rates for groups ranged from 19.0 to 44.4

\footnotetext{
${ }^{1}$ U.S. Geological Survey

${ }^{2}$ U.S. Fish and Wildlife Service
} 
centimeters per minute $[\mathrm{cm} / \mathrm{min}])$ and the fastest dewatering rate $(16 \mathrm{in} / \mathrm{h})$ is equivalent to less than $6.8 \mathrm{~cm} / \mathrm{min}$. Only the slowest movement rate measured, $6.6 \mathrm{~cm} / \mathrm{min}$ for one individual lamprey, was slower than the fastest dewatering rate.

We also investigated lamprey responses to a series of dewatering and rewatering events. Individual larvae were held in cylinders and exposed to four cycles of dewatering and rewatering using dewatering rates of 1 and $16 \mathrm{in} / \mathrm{h}$ and a rewatering rate of $2 \mathrm{in} / \mathrm{h}$. Each dewatering rate was tested under both dark and light conditions. The location of fish, either on the surface of the sediment or burrowed, was recorded after each dewatering event for four rounds. The most common individual fish response for all study groups was to remain burrowed through all four rounds, and there were large differences in response between small and large larvae. Overall for small larvae, combining all groups, 14 of 28 fish emerged, and of those, 8 died and 1 was lethargic. The 1 -in/h rate had 7 of the 8 mortalities, split about equally between the dark ( 3 fish) and light (4 fish) trials. All but one fish that died emerged from the sediment at some point during the four rounds of dewatering. Large larvae predominantly remained burrowed in all four rounds and did not experience any mortality. None of the large fish emerged for more than a single round, and emergence occurred only in the first and second rounds. Larvae emerged more quickly as the number of dewatering events increased. The mean time to emerge after the surface of the sediment in the tube was dewatered, combing all four groups, was 42 minutes (min) in round 1 (14 fish), $16 \mathrm{~min}$ in round 2 ( $5 \mathrm{fish}$ ), $11 \mathrm{~min}$ in round 3 ( $3 \mathrm{fish}$ ), and 8 minutes in round 4 (3 fish). When all groups and rounds of dewatering were combined, the overall mean time to emerge was 29 min (25 fish) and ranged from 1 min to 2 hours after the surface of the sediment was dewatered. Larvae burrowed deeper during the 1 -in/h trials than the 16 -in/h trials, and few fish were deeper than about 23 centimeters $(\mathrm{cm})$. Large larvae burrowed deeper than small larvae. Small larvae were most concentrated from 0 to $7.6 \mathrm{~cm}$ ( 83.7 percent), and large fish were concentrated from 15.2 to $22.8 \mathrm{~cm}$ (43.3 percent). The second dewatering event resulted in greater mean burrowing depth than the first event, but trends after the second event were less clear.

Larval size played a role in lamprey responses to dewatering, having a significant effect on emergence, movement rate, and vertical distribution. The sediment used for laboratory testing or occupied by lamprey in the field appears to affect lamprey response to dewatering and deserves greater attention in future studies. Larvae were more active in the dark, but darkness did not consistently provide better outcomes (e.g., more emergence or reduced stranding) compared to daylight. An improved understanding of the cues that prompt larvae to emerge from the sediment, combined with the ability to manage dewatering rates, would be useful to guide future dewatering events to minimize negative effects to lamprey.

\section{Introduction}

Pacific lamprey (Entosphenus tridentatus) numbers in the Columbia River Basin have decreased from historical levels (Close and others, 2002; Wang and Schaller, 2015; Clemens and others, 2017), which has raised concerns from managers of Federal, State, and Tribal entities. Recovery planning is hindered by a lack of information on the basic biology and ecology of lampreys, including limiting factors such as anthropomorphic effects on habitat. Larval lamprey spend 3 to 10 years of their lives burrowed in river sediments, where they filter feed on detritus and organic matter, making them vulnerable to water-level fluctuations that can dewater their habitat. Dewatering events occur regularly in the Columbia River Basin for several reasons, including operation and management of hydropower facilities, seasonal or maintenance closures 
of irrigation diversions, and in-water construction projects for habitat restoration, including culvert or bridge repair or replacement. Hundreds to thousands of dewatered larval lamprey have been documented during annual seasonal closures of irrigation diversions, and salvage efforts are sometimes used to capture and relocate these fish (Beals and Lampman, 2018; Skalicky and others, 2019). Guidance on best practices to limit adverse effects on lamprey during planned dewatering events like seasonal closures of an irrigation diversion or in-water construction projects is lacking. Few studies have evaluated dewatering practices, although field observations during salvage operations indicate that slower dewatering rates may be more protective for lamprey than faster rates (Beals and Lampman, 2018). Liedtke and others (2015) compared two dewatering rates in a controlled laboratory setting and reported that fewer larval lamprey were stranded at 3 inches per hour (in/h) than at $20 \mathrm{in} / \mathrm{h}$. Additional studies addressing dewatering rates and light conditions (day or night) are needed to provide effective guidance for planned dewatering events that allow lamprey the best opportunity to relocate water successfully and avoid being stranded.

The current study was designed to complement evaluations conducted by Liedtke and others (2015) by expanding the range of dewatering rates and including variable light conditions. Our initial evaluation of lamprey responses to dewatering (Liedtke and others, 2015) compared rates of 3 and $20 \mathrm{in} / \mathrm{h}$ during daylight conditions. To help determine dewatering rates that might be included in the current study, we met with State and Tribal partners who often work to salvage lamprey after dewatering events. Through discussion, we selected five dewatering rates ranging from 1 to $16 \mathrm{in} / \mathrm{h}$ that would be tested during both dark and light conditions. Lamprey have increased activity at night (Moursund and others, 2000; Goodman and others, 2015; Moser and others, 2015), which might encourage initiation of movement in response to dewatering more quickly at night compared to during the day. Lamprey might also have variable movement rates or other behaviors that could result in fewer fish being stranded on dewatered substrate during darkness.

A period of rewatering following a dewatering event may result in improved salvage opportunity if additional larvae emerge from the sediment where they can be collected and relocated. During a daytime dewatering event that occurred at the Fivemile-Bell Restoration Project on the Oregon coast, salvage was conducted by locating and collecting larvae that emerged from the sediment and relocating them to watered habitat. Overnight, dewatering was halted (pumps were turned off) and seepage caused the water level to rise, rewatering larval habitat that had previously been dewatered. When dewatering continued the following day, additional larvae emerged from areas where salvage had previously been conducted (Paul Burns, U.S. Forest Service, oral commun., 2019). Evaluations in the laboratory (Liedtke and others, 2015) and field (Skalicky and others, 2019) have shown that approximately 50 percent of larvae emerge from the sediment following dewatering and could potentially be removed from the surface of the sediment and salvaged. If repeated dewatering and rewatering could encourage approximately 50 percent of larvae to emerge each cycle, then most larvae (about 93 percent) in an area could potentially be salvaged after four cycles. To test this theory, we tested a repeated dewatering and rewatering approach using 1 - and $16-\mathrm{in} / \mathrm{h}$ dewatering rates, a 2 -in/h rewatering rate, and dark and light conditions. 
This study evaluated the effects of several dewatering approaches on larval Pacific lamprey. The objectives of this controlled laboratory study were to document the response of larval lamprey to dewatering of their habitat under dark and light conditions, specifically - (1) their movements relative to dewatering rate and fish size, resulting in their either being stranded or regaining access to water, and (2) their emergence behavior during repeated dewatering and rewatering relative to dewatering rate, light condition, and fish size.

\section{Methods}

\section{Fish Source, Size, and Maintenance}

Larval lamprey were collected using lamprey-specific electrofishing settings and sediment grab samples from the Wind River, Washington. Larvae longer than 60 millimeters $(\mathrm{mm})$ can be identified to species, allowing separation of Pacific lamprey from sympatric Western Brook lamprey (Lampetra richardsoni). We wanted to include larvae less than $60 \mathrm{~mm}$ in our tests to increase the overall size range but could not confirm they were Pacific lamprey. Of the larvae identified to species, 88.3 percent were Pacific lamprey, so we assume that the proportion would be similar in the group of small lamprey that could not be identified.

Fish were transported to the Columbia River Research Laboratory in Cook, Washington, and held in fiberglass tanks $(51 \times 43 \times 27 \mathrm{~cm})$ with beach sand for burrowing at a depth of about 5 $\mathrm{cm}$ and supplied with heated $\left(8.5-13.6\right.$ degrees Celsius $\left.\left[{ }^{\circ} \mathrm{C}\right]\right)$, filtered water $(1.5$ liters per minute $[\mathrm{L} / \mathrm{min}])$ from the Little White Salmon River. Lamprey were fed a slurry of active yeast and commercial fry food (Gemma Wean 0.1; Skretting, Vancouver, British Columbia, Canada) using methods modified from Rose and Mesa (2012).

During field collections of larvae we defined three size classes - fish less than $57 \mathrm{~mm}$, $58-84 \mathrm{~mm}$, and greater than $85 \mathrm{~mm}$ total length (TL). For dewatering trials, larvae were selected from each size class in approximately equal numbers to include the full range of sizes available. Individual larvae were not reused for multiple experiments, so all trials used nonexposed or naïve fish. To best represent larvae in natural systems and minimize long-term laboratory holding, we acclimated fish for 2 weeks prior to any testing and completed all tests within 6 weeks of the date of collection. We collected larvae on four occasions (June-August 2019) to ensure an adequate number of fish and sufficient time to execute all study trials. Tests of movement rate were an exception in that the larvae were not naïve and some were held for longer than 6 weeks as a result of fish shortages.

\section{Movement Trials}

To test larval lamprey movements in response to dewatering, we built a wooden tank $(239 \times 30 \times 91 \mathrm{~cm})$ with a false bottom at a 10 -percent slope $\left(5.7^{\circ}\right)$ and coated it with epoxy paint (fig. 1). A drain was placed at one end with a perforated divider positioned $29 \mathrm{~cm}$ from the end to hold the substrate in place but allow water to drain from the tank. The tank was filled to a depth of $22.9 \mathrm{~cm}$ with sediment, maintaining the 10-percent slope. The sediment used in the tank was collected from the mouth of White Salmon River, Washington, and had a median particle size of $0.445 \mathrm{~mm}$ (medium sand). The tank was portioned into four sections (fig. 1). Sections 1 and 4 were $30.5 \mathrm{~cm}$ long, and sections 2 and 3 were $74.5 \mathrm{~cm}$ long. The tank received heated river water $(3 \mathrm{~L} / \mathrm{min})$ whose temperature ranged from 9.2 to $9.6{ }^{\circ} \mathrm{C}$. 


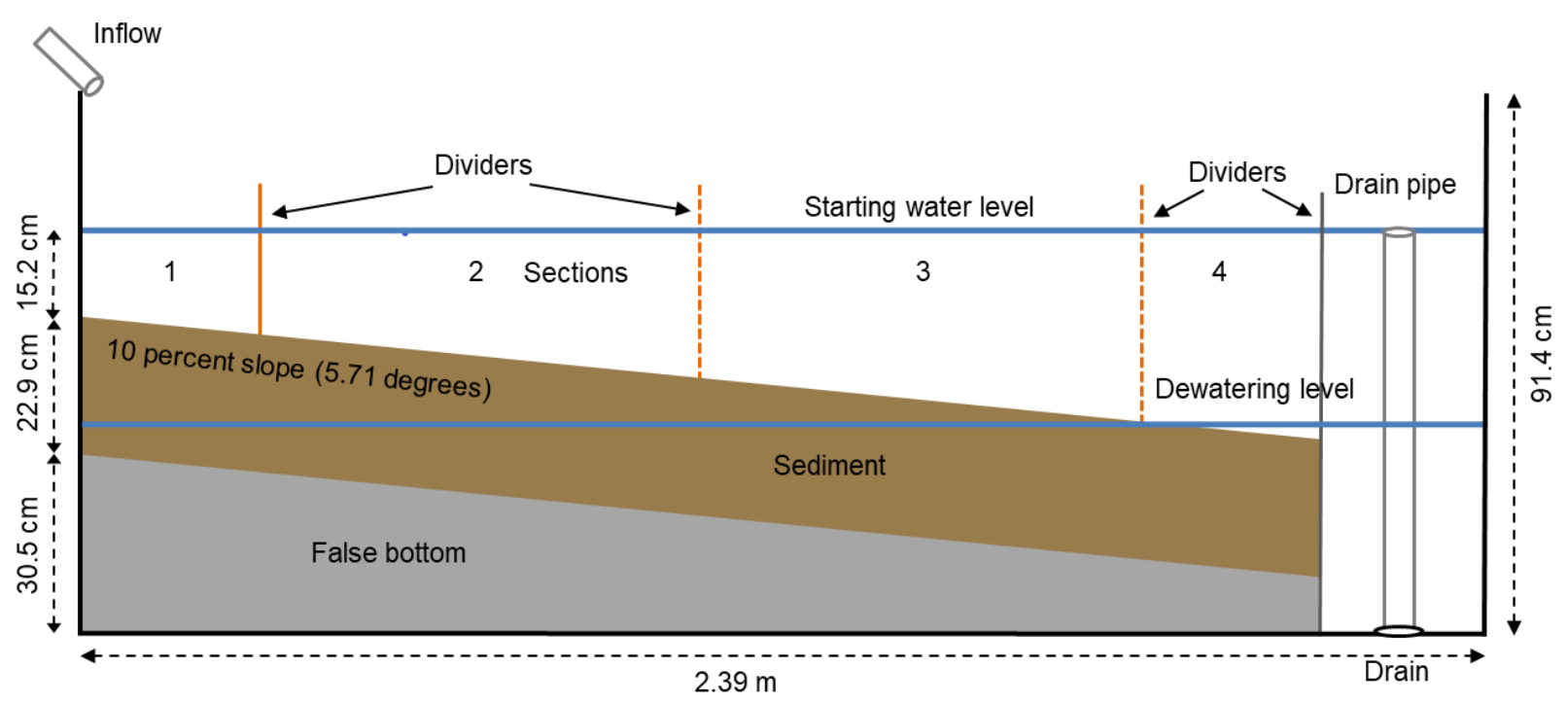

Figure 1. Schematic diagram of the tank constructed to evaluate larval lamprey movements in response to dewatering. The tank was sloped at a 10-percent grade, filled with sediment, and divided into four sections. Dividers between tank sections 1 and 2 and between tank section 4 and the drain were physical dividers (solid lines) and dashed lines represent divisions used descriptively. The elevations of the starting and final dewatering water levels are shown by horizontal blue lines. (cm, centimeters; $\mathrm{m}$, meters)

Five dewatering rates were tested, each under dark and light conditions. The dewatering rates were selected to further the work conducted by Liedtke and others (2015) using larval lamprey in the same test system and to be relevant to dewatering rates observed regionally. We tested dewatering rates of $1,1.8,4,8$, and $16 \mathrm{in} / \mathrm{h}$. Liedtke and others (2015) compared results from rates of 3 and $20 \mathrm{in} / \mathrm{h}$. We selected $1.8 \mathrm{in} / \mathrm{h}$ as a test rate because it was used for a dewatering event in the field where larval lamprey response and salvage techniques were evaluated (see Skalicky and others, 2019). The tank was dewatered at one of the test rates, to the point where tank sections 1 to 3 had exposed substrate, and the only surface water available was in tank section 4 , where water covered the full length of the substrate. We completed three replicate trials of each rate and light condition using 10 larvae per trial. The combination of dewatering rate and light condition resulted in 10 study groups: $1 \mathrm{in} / \mathrm{h}$ dark (1-D), $1 \mathrm{in} / \mathrm{h}$ light (1-L), $1.8 \mathrm{in} / \mathrm{h}$ dark (1.8-D), $1.8 \mathrm{in} / \mathrm{h}$ light (1.8-L), 4 in/h dark (4-D), 4 in/h light (4-L), 8 in/h dark (8-D), 8 in/h light (8-L), 16 in/h dark (16-D), and 16 in/h light (16-L). Additionally, three control trials were completed under both dark (C-D) and light (C-L) conditions, where the tank was not dewatered. Twelve study groups with three replicates per group resulted in 36 dewatering trials. All trials used a 1-h waiting period after trial conditions were established in the tank, after which fish were located and removed.

To stock fish, the tank was filled with water and a metal divider was pushed into the substrate to the bottom of the tank at the lower border of section 1 to prevent fish from moving out of section 1 . Ten fish ( $2-5$ fish from each size class) were haphazardly selected and placed in section 1. After all fish burrowed into the substrate, the inflow water was turned on and the fish 
remained in section $1 \mathrm{a}$ minimum of $12 \mathrm{~h}$. To begin a trial, the inflow water was turned off, the drain pipe and the section 1 metal divider were removed, and the drain valve was set to the test dewatering rate. The tank was checked regularly, and adjustments were made as necessary to maintain the desired test rate. Once the final dewatering level was reached (water available only in tank section 4), the drain valve was closed, air and water temperature were recorded, and the 1-h waiting period began. Larval movements were monitored closely to help determine final tank position and time of emergence from the sediment. At the completion of the waiting period the trial was terminated. We located each fish and recorded the tank section and whether they were on the surface of the substrate or burrowed into the substrate. To locate burrowed fish, sediment was removed with a scoop, placed on a sieve over a container, and gently sprayed with water. Following removal from the tank, larvae were anesthetized in a solution of tricaine methanesulfonate (100 milligrams per liter $[\mathrm{mg} / \mathrm{L}])$ and buffered with an equal amount of sodium bicarbonate to facilitate collection of weight and length data. Control trials followed the same procedures, except that the tank was not dewatered and the waiting period began as soon as the inflow was turned off and the divider for section 1 was removed.

Dark and light trials were conducted using natural light conditions, and we used red light to monitor fish during dark trials. The $1-\mathrm{in} / \mathrm{h}$ dewatering rate required almost $13 \mathrm{~h}$ to reach the final dewatering level, and it was impossible to execute fully in darkness because the trials were conducted during the summer. The other dewatering rates required less than $8 \mathrm{~h}$ of a constant light condition and were more manageable. For the 1-in/h trials, we ensured that the targeted light condition was reached when the water level reached the surface of the substrate. Dewatering of the substrate was always executed under the target light condition. If periods of the nontarget light condition had to be included, we planned the trial so they occurred before the water level reached the substrate, when lamprey were less likely to be moving (on the basis of our observations from Liedtke and others [2015]).

\section{Movement Rates}

We estimated larval movement rates in the test tank under dark and light conditions to aid in interpretation of stranding risk during movement trials. On the basis of Liedtke and others (2015), we anticipated the largest difference in movement rates between the smallest and largest larvae, so we did not measure movement rates for mid-sized fish. Initially we placed 10 larvae in tank section 1 while the tank was watered, allowed them to burrow and acclimate briefly, and then rapidly dewatered the tank. We planned to monitor larvae as they emerged from the sediment and moved down the tank slope. After several attempts in which few fish emerged or moved, we modified our approach. We selected fish and gently placed them on the surface of the sediment in tank section 1 shortly after the tank was dewatered. As fish began moving, we noted the time and their initial location. When a fish stopped moving, we noted the time and its final location. The total horizontal distance between the initial and final locations was measured and recorded as a movement. The total distance moved and total time were used to calculate a travel rate. Some larvae moved, stopped briefly, and then continued. If the period of inactivity was less than about 20 seconds (s), we continued monitoring the movement. If inactivity was more than about $20 \mathrm{~s}$, we considered the first movement complete and monitored for initiation of additional movements. A second or third movement for the same individual was measured and reported unless inactivity exceeded about $2 \mathrm{~min}$; then recording for that individual was terminated. Movement rates were reported for small and large fish under dark and light conditions. The 
maximum horizontal distance larvae could move in the tank, from the lower margin of section 1 to the upper margin of the water in section 4, was $149 \mathrm{~cm}$.

Larval lamprey move using a serpentine motion such that forward motion is typically accompanied by lateral movements. To estimate the amount of lateral movement we observed as we measured movement rates, we divided the width of the tank into three lanes, each $10.2 \mathrm{~cm}$ wide. To help visualize the lanes when lamprey were moving in the tank, we suspended string at the lane boundaries, a few centimeters above the surface of the sediment. We recorded the lane where lamprey initiated and ended each movement. To be assigned to a lane, the lamprey's entire body had to cross the lane boundary.

\section{Repeated Dewatering and Rewatering Trials}

Repeated dewatering and rewatering trials were conducted using two dewatering rates (1 and $16 \mathrm{in} / \mathrm{h}$ ) and dark and light conditions. Larvae were held in sediment-filled (15.2-cmdiameter) plastic tubes positioned in tanks, and tanks were dewatered and rewatered four times for each trial. The dewatering rate was set to one of the two test rates, and the rewatering rate was $2 \mathrm{in} / \mathrm{h}$ for all trials. A similar test system was used in Liedtke and others (2015) to evaluate survival of larvae after dewatering. We had two objectives for these trials: (1) describe the response of individual larvae to four rounds of dewatering and rewatering, specifically which fish emerged from the sediment each round; and (2) describe the vertical distribution of larvae following each round of dewatering. Trials for both objectives were completed simultaneously, with slightly different test systems. Controls were configured like the vertical distribution test system but supported both objectives.

\section{Individual Fish Response}

To describe individual fish response, we put one larval lamprey into a 15.2-cm-diameter plastic tube, $38.1 \mathrm{~cm}$ tall, filled with $30.5 \mathrm{~cm}$ of sediment. The sediment was the same material used in the movement trials. The tube bottoms were covered with nylon bolt cloth (aperture of 425 micrometer $[\mu \mathrm{m}])$ to allow water to drain. Seven treatment tubes were haphazardly placed on the bottom of a 1.22-meter-diameter fiberglass tank and two control tubes were placed in an adjacent, equivalent tank. Control tubes were modified slightly from treatment tubes, to match the vertical distribution treatment group (see below). Two replicates of each treatment were completed simultaneously, in separate tanks. For each trial, there were three tanks: a control tank with two tubes, and two treatment tanks, each with seven treatment tubes.

Prior to a trial, tanks were filled with water until the level was just above the sediment surface in the tubes to facilitate stocking of one test fish per tube. When all fish were stocked, the tops of the tubes were covered with mesh, the tanks were filled to a depth of $39 \mathrm{~cm}$, and fish were allowed to acclimate for at least $14 \mathrm{~h}$. Water temperatures in the tanks ranged from 8.8 to $10.3{ }^{\circ} \mathrm{C}$. At the start of a trial, the inflow to the treatment tanks was turned off and the tanks were drained with a siphon at the target dewatering rate. After the water level in the tanks was below the top of the tubes, the mesh covering was removed for improved visibility. Tubes were monitored and time of emergence was recorded if observed. When the tank was completely drained, the 1-h waiting period began. At the end of the waiting period, the location of the fish in each tube was recorded as either burrowed in the sediment or on the surface of the sediment, and the first round of dewatering was complete. The tank inflow was set to refill the tanks at $2 \mathrm{in} / \mathrm{h}$ to begin the second round of the trial. Four rounds of repeated dewatering and rewatering were completed for each of four trials: 1-D, 1-L, 16-D, and 16-L. 


\section{Vertical Distribution}

To describe the vertical distribution of larvae, we modified the plastic tubes used for the individual response objective. The 15.2-cm-diameter plastic tubes, $38.1 \mathrm{~cm}$ tall, were partitioned into four sections. The three lower sections were $7.6 \mathrm{~cm}$ tall, and the top section was $15.2 \mathrm{~cm}$ tall. The four tube sections were stacked, secured in a column using neoprene sleeves, and filled with $30.5 \mathrm{~cm}$ of sediment. The top tube section had $7.6 \mathrm{~cm}$ of sediment and $7.6 \mathrm{~cm}$ of unfilled space to allow fish access to the surface of the substrate. Four vertical distribution tubes were haphazardly placed into each of the two treatment tanks, and two control tubes (with the same configuration) were placed in the adjacent, control tank. Tubes were stocked with two larvae (one small and one large) and acclimated with the individual fish response tubes.

Two tubes (one from each treatment tank) were randomly assigned to each of the four dewatering rounds. Tubes were dewatered and rewatered for 1 to 4 rounds with the individual fish response tubes (they were in the same tanks). At the completion of each round (after the 1-h waiting period), the tubes preassigned to that round were removed from the tank. Fish on the surface were removed and counted. The top neoprene sleeve was removed, and the top tube section was slid quickly onto an adjacent tray. The next two sections were removed in the same manner. Sediment from each tube section was searched to determine the depth stratum where each fish was burrowed. Fish were counted, anesthetized, weighed, and measured. Control tubes were processed using the same procedure, except that the tank was not dewatered.

We selected small and large larvae for these trials and report findings based on these size categories. Fish were classified as small if their total length (TL) was about 35 to $70 \mathrm{~mm}$ and as large if their TL was at least about $85 \mathrm{~mm}$. Larvae between these size categories were not used to reduce the total number of larvae collected for the study and because we anticipated the greatest difference in response to result from the difference in TL.

\section{Data Analysis}

In the movement trials, we pooled the three replicate trials for each of the 12 study groups and present mean findings for each group. At the end of each movement trial we recorded fish position in the tank by noting the tank section and whether fish was on the surface of the sediment or burrowed. For analysis, we categorized larvae as either safe or stranded. Fish were considered safe if they were in tank section 4, either on the surface or burrowed in the sediment. Larvae outside tank section 4 (on the surface or burrowed) were classified as stranded. The proportion of fish that emerged from the sediment was calculated by summing the number of fish observed to emerge in tank section 1 (but not leave section 1) and the number of fish that moved out of section 1. Fish that moved outside tank section 1 were included because we assumed, on the basis of Liedtke and others (2015), that movement out of section 1 required emerging from the sediment and traveling over the surface. Time of emergence was monitored and documented opportunistically, and we summarized the time to emerge as the amount of time after the surface sediment in tank section 1 was fully exposed. The surface of the sediment in tank section 1 was dewatered in $7.2 \mathrm{~h}$ for $1 \mathrm{in} / \mathrm{h}, 4.0 \mathrm{~h}$ for $1.8 \mathrm{in} / \mathrm{h}, 1.8 \mathrm{~h}$ for $4 \mathrm{in} / \mathrm{h}, 54$ minutes for $8 \mathrm{in} / \mathrm{h}$, and 27 minutes for $16 \mathrm{in} / \mathrm{h}$.

In the repeated dewatering and rewatering trials, we pooled the replicates for each study group and present mean findings by group. For vertical distribution trials, the number and proportion of fish were summarized by the stratum (1-4) in the sample tube where fish were recovered. Mean depth stratum was calculated using the stratum for each individual fish in a group. Emergence timing was calculated as the movement trials were, beginning when the 
surface of the sediment in the tubes was dewatered. The surface of the sediment was exposed 3.2 $\mathrm{h}$ after dewatering started for the $1 \mathrm{in} / \mathrm{h}$ rate and 13 minutes after dewatering started for the 16 $\mathrm{in} / \mathrm{h}$ rate.

Comparisons of fish size and movement rate were made using t-tests or analysis of variance (ANOVA) and Duncan's Multiple Range Test at a significance level of 0.05.

\section{Results}

\section{Movement Trials}

We completed 36 dewatering trials for the 12 study groups during June 3-September 11, 2019, using 360 larvae (table 1). Water and air temperatures during trials were similar across all groups (table 1) and the mean TL of larvae for the groups were not significantly different $(\mathrm{F}=0.12, \mathrm{df}=11, p=0.99$; fig. 2 ). The amount of time required to reach the dewatering level ranged from 49 minutes for the 16 -in/h rate to almost $13 \mathrm{~h}$ for the 1 -in/h rate (table 2 ).

Table 1. Summary of 36 dewatering trials conducted in 2019 to monitor larval lamprey movements, including dewatering group, trial dates, mean water temperature, and mean air temperature.

[Group names are a combination of dewatering rate $(1,1.8,4,8$, or 16 inches per hour) and dark (D) or light (L) conditions; C, control; ${ }^{\circ} \mathrm{C}$, degrees Celsius; SD, standard deviation]

\begin{tabular}{lccc}
\hline \multicolumn{1}{c}{ Group } & Trial dates & $\begin{array}{c}\text { Mean water temperature } \\
\left({ }^{\circ} \mathrm{C}\right)(\mathrm{SD})\end{array}$ & $\begin{array}{c}\text { Mean air temperature } \\
\left({ }^{\circ} \mathrm{C}\right)(\mathrm{SD})\end{array}$ \\
\hline 1-D & 12 June-23 July & $9.3(0.2)$ & $19.6(1.7)$ \\
1-L & 10 June-15 July & $9.5(0.2)$ & $19.1(0.9)$ \\
1.8-D & 6 June-18 July & $9.3(0.1)$ & $18.0(1.6)$ \\
1.8-L & 3 June-8 July & $9.3(0.3)$ & $19.3(0.6)$ \\
4-D & 5 June-16 July & $9.3(0.1)$ & $18.9(1.6)$ \\
4-L & 4 June-12 July & $9.3(0.1)$ & $18.8(1.1)$ \\
8-D & 27 June-11 September & $9.3(0.1)$ & $18.1(0.7)$ \\
8-L & 26 June-22 July & $9.2(0.3)$ & $19.6(1.4)$ \\
16-D & 16 June-20 August & $9.6(0.3)$ & $19.2(1.0)$ \\
16-L & 11 June-13 August & $9.2(0.1)$ & $18.9(0.7)$ \\
C-D & 22 June-21 August & $9.4(0.1)$ & $18.8(2.0)$ \\
C-L & 14 June-14 July & $9.4(0.2)$ & $19.6(1.5)$ \\
\hline
\end{tabular}


Table 2. Mean time required to reach the test water level in movement trials conducted under dark and light conditions for five dewatering rates. Each rate and light condition is a mean of three replicate trials. [in/h, inches per hour; h, hours; SD, standard deviation]

\begin{tabular}{ccc}
\hline Rate (in/h) & Dark (h) (SD) & Light (h) (SD) \\
\hline 1 & $12.78(0.14)$ & $12.76(0.12)$ \\
1.8 & $7.09(0.02)$ & $7.19(0.03)$ \\
4 & $3.16(0.06)$ & $3.23(0.03)$ \\
8 & $1.60(0.06)$ & $1.66(0.05)$ \\
16 & $0.82(0.01)$ & $0.83(0.01)$ \\
\hline
\end{tabular}

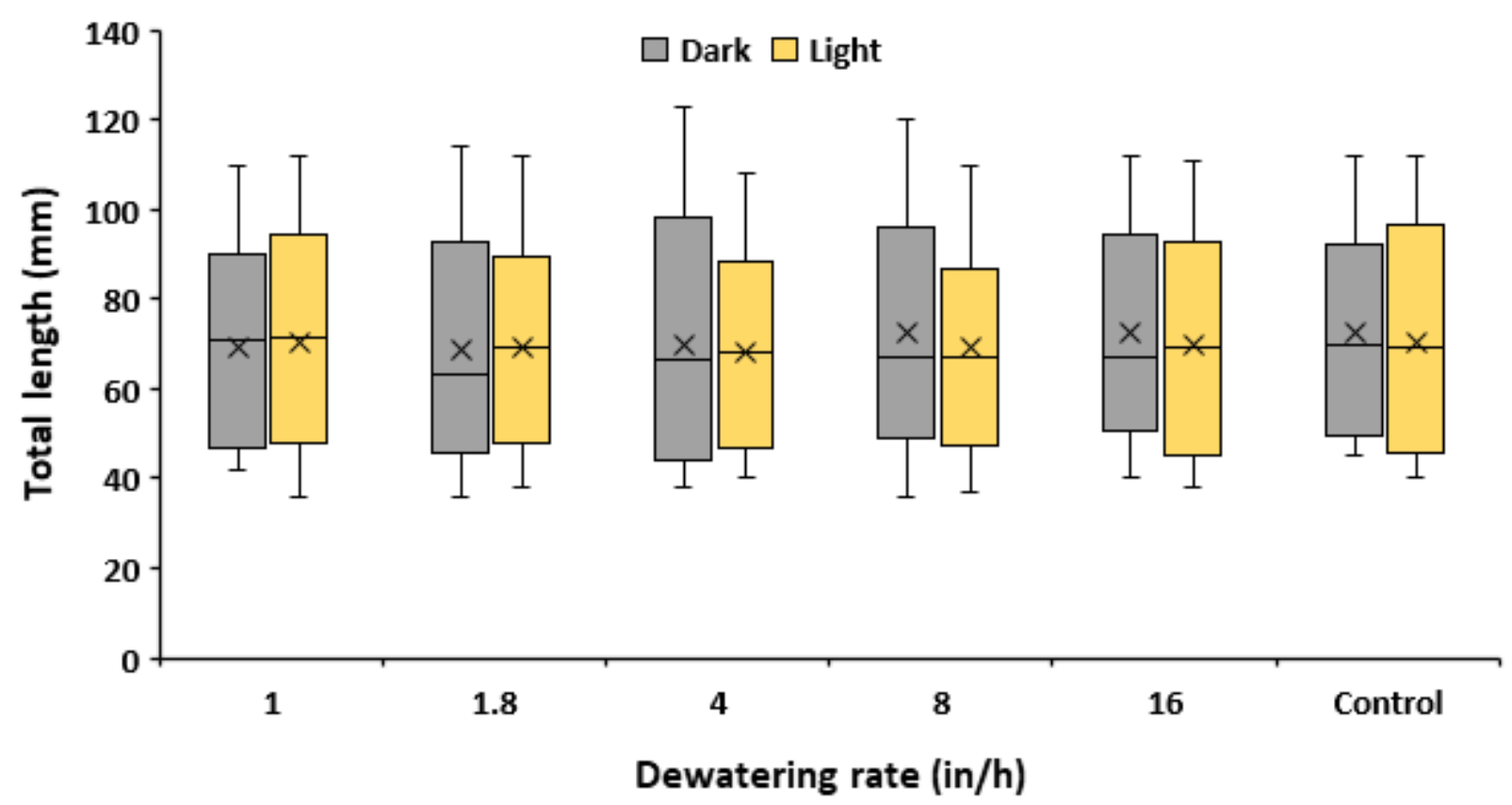

Figure 2. Distribution of larval lamprey total length in movement trials for dark and light conditions at each of five dewatering rates and for controls. Controls were not dewatered. On each bar, means are indicated with an $\mathrm{X}$, and medians with a line; the ends of the bars represent the minimum and maximum values. (inches per hour, in/h; $\mathrm{mm}$, millimeter)

Larvae in the control groups, which did not experience dewatering, stayed predominantly in tank section 1. In the $\mathrm{C}-\mathrm{L}$ group, 93.3 percent of the fish remained in section 1 and two fish (6.7 percent) were recovered in the uppermost part of section 2, near the border with section 1. The C-D group showed more movement, with 86.7 percent of the larvae recovered in tank section 1 and 13.3 percent outside section 1 . One of the four fish that moved outside section 1 was in the uppermost part of section 2. The three other larvae were in section 3 (two fish) or the middle of section 2 (one fish) at the end of the trial.

All study groups experienced high rates of stranding. The slower dewatering rates stranded fewer fish than the faster rates, and there was no clear reduction in stranding rate under dark conditions compared to light (fig. 3). The lowest stranding rates were for $1-\mathrm{L}$, with 76.7 
percent stranded, and 1-D, with 80.0 percent stranded. All larvae (100 percent) were stranded in the 8-D, 16-D, and 16-L groups (fig. 3). At each of the five dewatering rates, trials conducted in the dark stranded the same or higher proportions of fish than the corresponding trial conducted in the light. In most cases, the differences in stranded proportions between the dark and light trials for a given rate were small. Two rates, $4 \mathrm{in} / \mathrm{h}$ and $16 \mathrm{in} / \mathrm{h}$, had the same stranding rate for dark and light trials. The largest difference between light conditions occurred at the 1.8 -in/h rate, with 86.7 percent of larvae stranded in the light and 96.7 percent stranded in the dark. There was a difference of 3.3 percent between light conditions for the 1 -in/h trials and a difference of 6.7 percent for the 8 -in/h trials. Statistical comparison of the mean TL of larvae that were stranded and safe was possible only for the $1-\mathrm{in} / \mathrm{h}$ rate, because only one to two fish were classified as safe for all other rates. There was no significant difference in mean TL of safe fish $(60.2 \mathrm{~mm}, 6$ fish) and stranded fish (71.9 mm, 24 fish $)(\mathrm{t}=1.14, p=0.26)$ in 1-D. In the 1-L group, however, safe fish were significantly smaller $(47.0 \mathrm{~mm}, 7 \mathrm{fish})$ than stranded fish $(77.7 \mathrm{~mm}, 23 \mathrm{fish})$ $(\mathrm{t}=3.33, p=0.002)$.

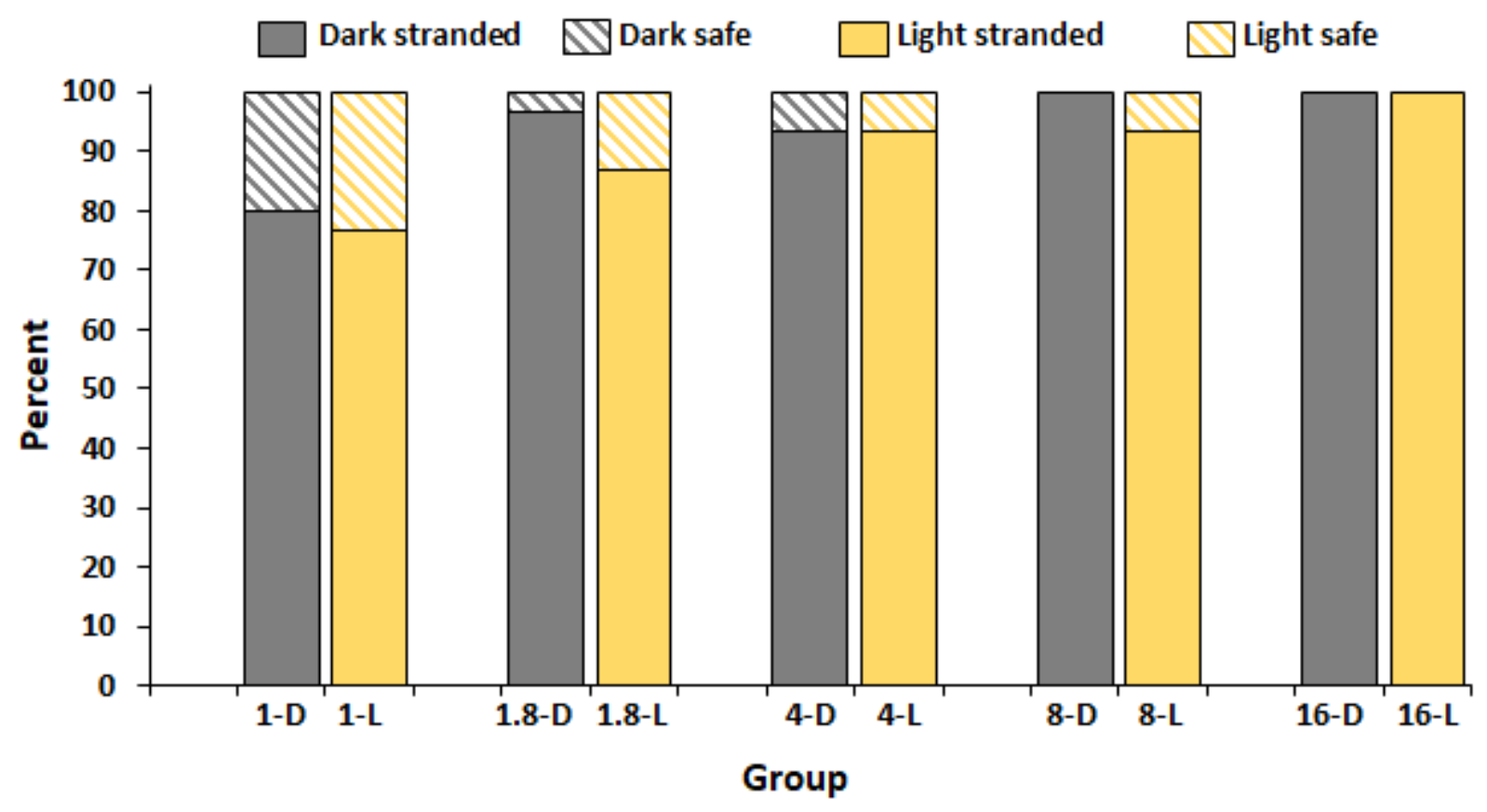

Figure 3. Graph showing percentage of larval lamprey that were stranded (in tank sections 1-3) or safe (in tank section 4) at the end of dewatering trials, by group. Group names are a combination of a dewatering rate $(1,1.8,4,8$, or 16 inches per hour (in/h)) and dark or light condition (D or L).

The largest contribution to stranding rates for all study groups was the high number of larvae that did not initiate movement in response to dewatering and remained in tank section 1. From 50.0 to 80.0 percent of larvae in the study groups were recovered in section 1 (fig. 4). Fewer fish were in section 1 at $1 \mathrm{in} / \mathrm{h}(50.0$ percent for $1-\mathrm{D}$ and 56.7 percent for $1-\mathrm{L})$ than other groups, and the highest proportions were for $4-\mathrm{D}$ (80.0 percent), 1.8-D (76.7 percent), and 8-D (76.7 percent). The dark and light conditions had similar numbers of fish that remained in section 1 , differing only by one to two fish for each rate. Overall, three of the five dewatering rates had higher numbers of fish in section 1 under dark conditions than under light conditions. 


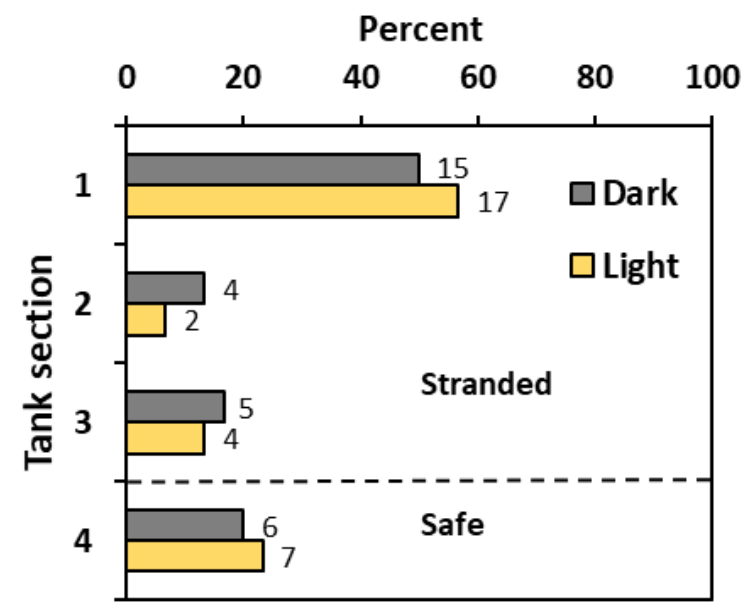

$1 \mathrm{in} / \mathrm{h}$

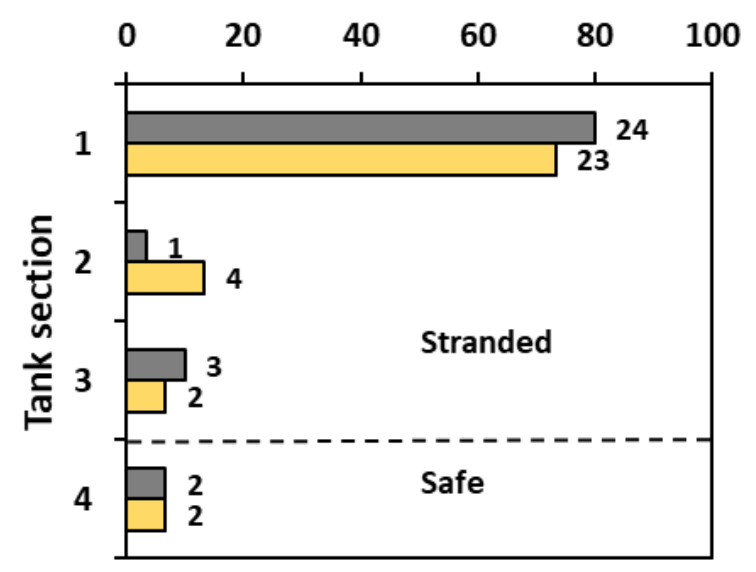

$4 \mathrm{in} / \mathrm{h}$

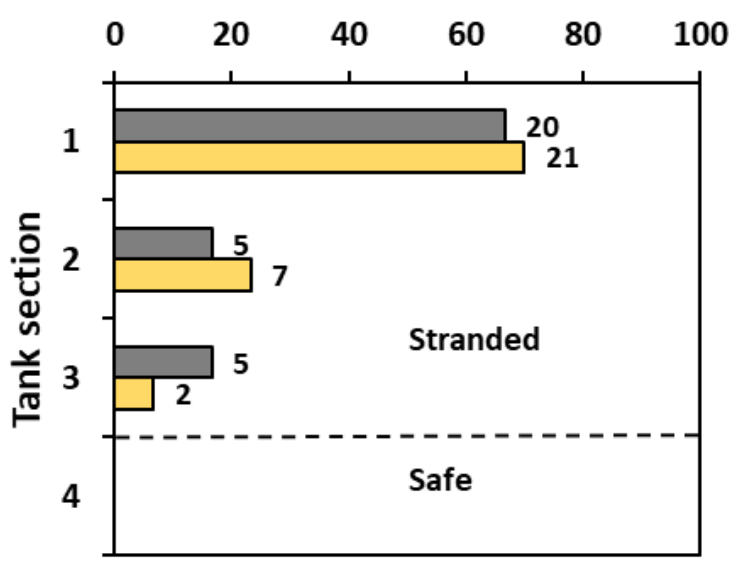

\section{$16 \mathrm{in} / \mathrm{h}$}

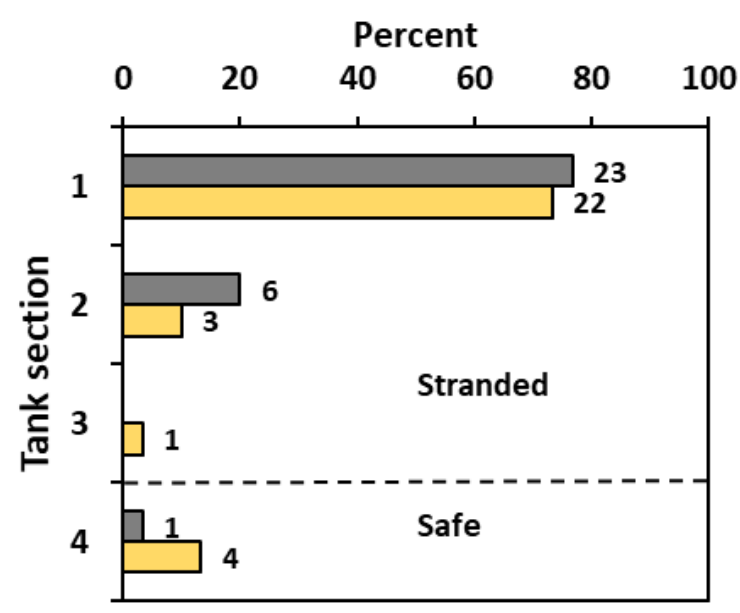

$1.8 \mathrm{in} / \mathrm{h}$

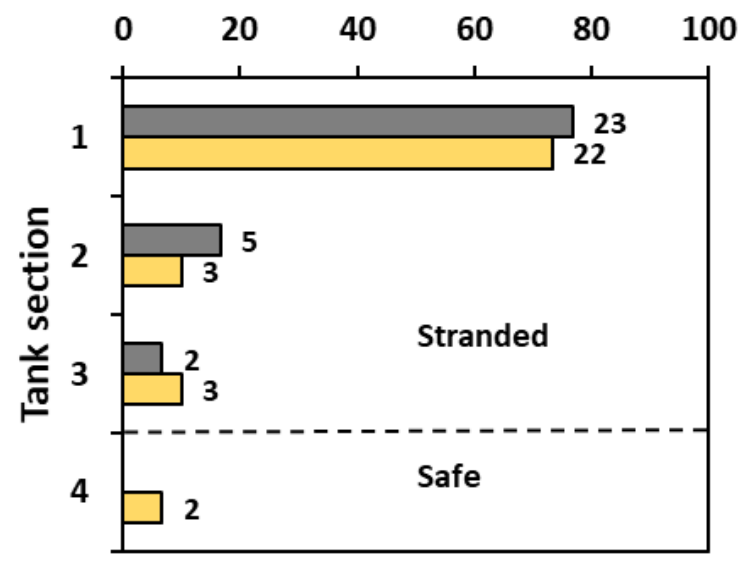

$8 \mathrm{in} / \mathrm{h}$

Figure 4. Graphs showing percentage of larval lamprey in each tank section at the end of movement trials conducted with five dewatering rates under dark and light conditions. Fish in sections 1 to 3 were categorized as stranded and fish in section 4 were considered safe. Numbers at ends of bars indicate number of fish. (in/h, inches per hour) 
Larvae that initiated movement in response to dewatering but were ultimately classified as stranded were most commonly found in tank section 2 . The 16-in/h dewatering rate had the highest proportion of fish stranded in section 2 or 3 (fig. 4), and of the 19 stranded fish, 12 (63.1 percent) were in section 2 (table 3 ). Three of the five dewatering rates had more fish stranded in section 2 than in section 3 . The exceptions were $4 \mathrm{in} / \mathrm{h}$, at which the same number of fish were in sections 2 and 3 , and $1 \mathrm{in} / \mathrm{h}$, at which more fish were in section 3 than in section 2 (table 3 ).

Overall, across the 10 study groups, 59.7 percent of fish that left section 1 but were ultimately stranded were recovered in section 2 and 40.3 percent were recovered in section 3 , closer to the water at the bottom of the slope.

Table 3. Summary of larval lamprey in movement trials that emerged from the sediment in tank section 1 and initiated movement toward tank section 4 but were ultimately classified as stranded because they did not reach tank section 4 prior to the end of the trial.

[Group names are a combination of dewatering rate $(1,1.8,4,8$, or 16 inches per hour) and dark (D) or light (L) conditions]

\begin{tabular}{|c|c|c|}
\hline Group & $\begin{array}{l}\text { Number of fish in } \\
\text { section } 2\end{array}$ & $\begin{array}{c}\text { Number of fish in } \\
\text { section } 3\end{array}$ \\
\hline 1-D & 4 & 5 \\
\hline $1-\mathrm{L}$ & 2 & 4 \\
\hline Total & 6 & 9 \\
\hline 1.8-D & 6 & 0 \\
\hline $1.8-\mathrm{L}$ & 3 & 1 \\
\hline Total & 9 & 1 \\
\hline 4-D & 1 & 3 \\
\hline $4-\mathrm{L}$ & 4 & 2 \\
\hline Total & 5 & 5 \\
\hline 8-D & 5 & 2 \\
\hline $8-\mathrm{L}$ & 3 & 3 \\
\hline Total & 8 & 5 \\
\hline $16-\mathrm{D}$ & 5 & 5 \\
\hline $16-\mathrm{L}$ & 7 & 2 \\
\hline Total & 12 & 7 \\
\hline Total (percentage) & $40(59.7)$ & $27(40.3)$ \\
\hline
\end{tabular}

The overall proportion of larvae that emerged from the sediment during dewatering trials was approximately 30 percent, and fish that emerged were consistently smaller than those that remained burrowed. The highest proportion of emerging larvae, 50.0 percent, was observed for 1-D; when all dewatering rates were combined, emergence was 31.3 percent for dark groups and 30.7 percent for light groups (fig. 5). Comparing across dewatering rates with dark and light 
conditions combined, the highest emergence was 45 percent for $1 \mathrm{in} / \mathrm{h}$, followed by 32 percent for $1.8 \mathrm{in} / \mathrm{h}$. The mean TL of fish that emerged was smaller than the mean TL of fish that remained burrowed in all study groups, and in 9 of the 10 groups, the size difference was statistically significant (fig. 5). Although this metric was not measured and recorded rigorously, observations made while digging in sediment to collect larvae indicate that smaller fish burrowed at shallower depths than larger fish.
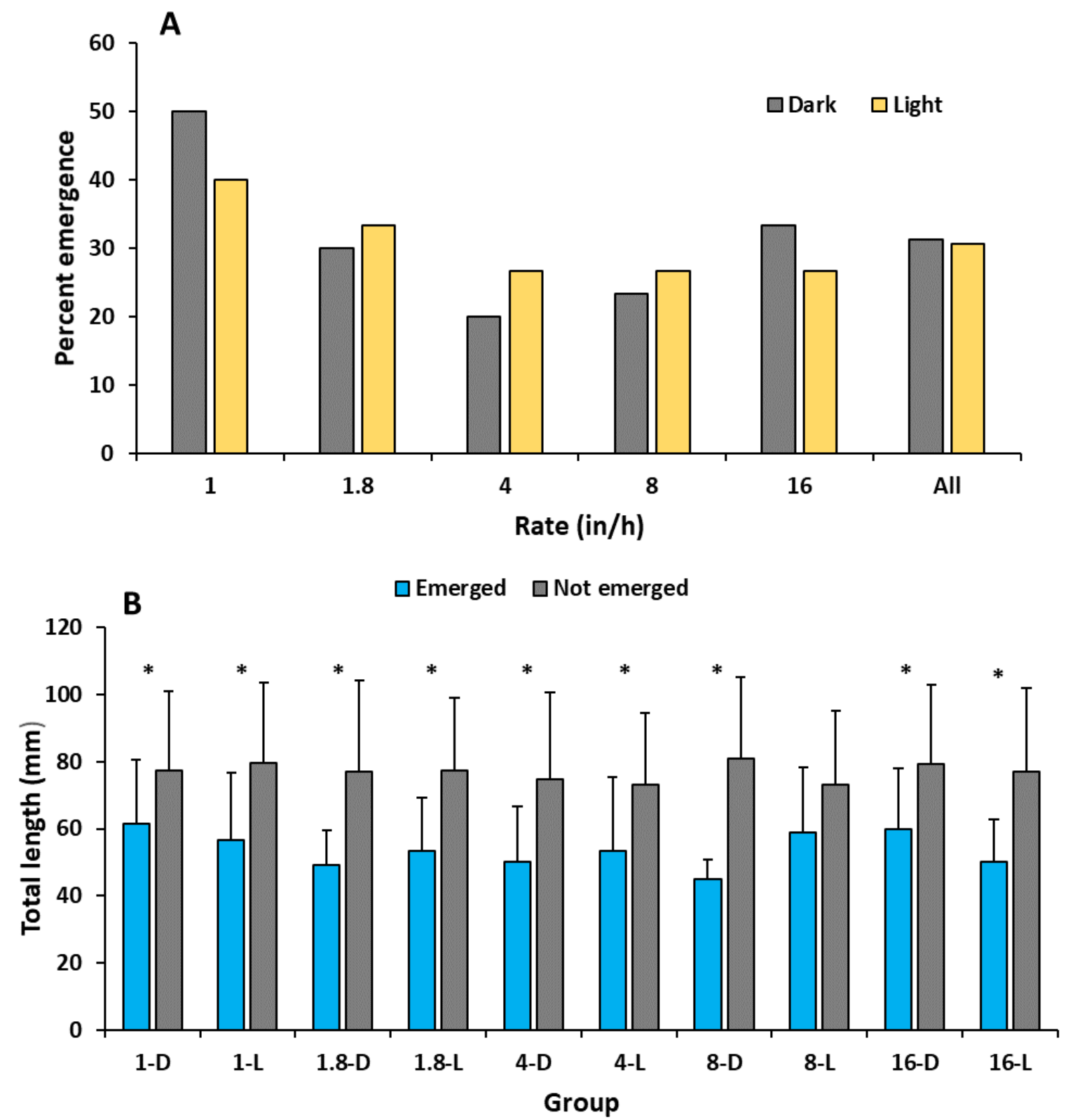

Figure 5. Graphs showing summary of percent emergence and total length for larval lamprey during dewatering trials at five dewatering rates under dark and light conditions. A, shows percent emergence for each dewatering rate and light condition and, B, shows the mean total length of larvae that emerged or did not emerge from the sediment in each study group. Error bars are the standard deviation. Asterisks indicate bars within a group that were statistically different as determined by t-tests. Group names are a combination of a dewatering rate $(1,1.8,4,8$, or 16 inches per hour (in/h) through $16 \mathrm{in} / \mathrm{h})$ and dark or light condition ( $\mathrm{D}$ or $\mathrm{L})$. 
The time of emergence for 58 larvae (62.4 percent of the total number that emerged) and their median time to emerge (after the surface of the sediment in tank section 1 was dewatered) was $0.62 \mathrm{~h}$ (range $0-4.5 \mathrm{~h}$ ). Because the dewatering period for the 1 -in/h trials was long, we only observed three larvae emerge, so this rate was excluded from analyses for emergence timing. The dark and light groups for each dewatering rate generally had similar median emergence times (fig. 6). The 1.8-L and 8-L groups had slightly higher median or maximum times relative to their corresponding dark groups (fig. 6).

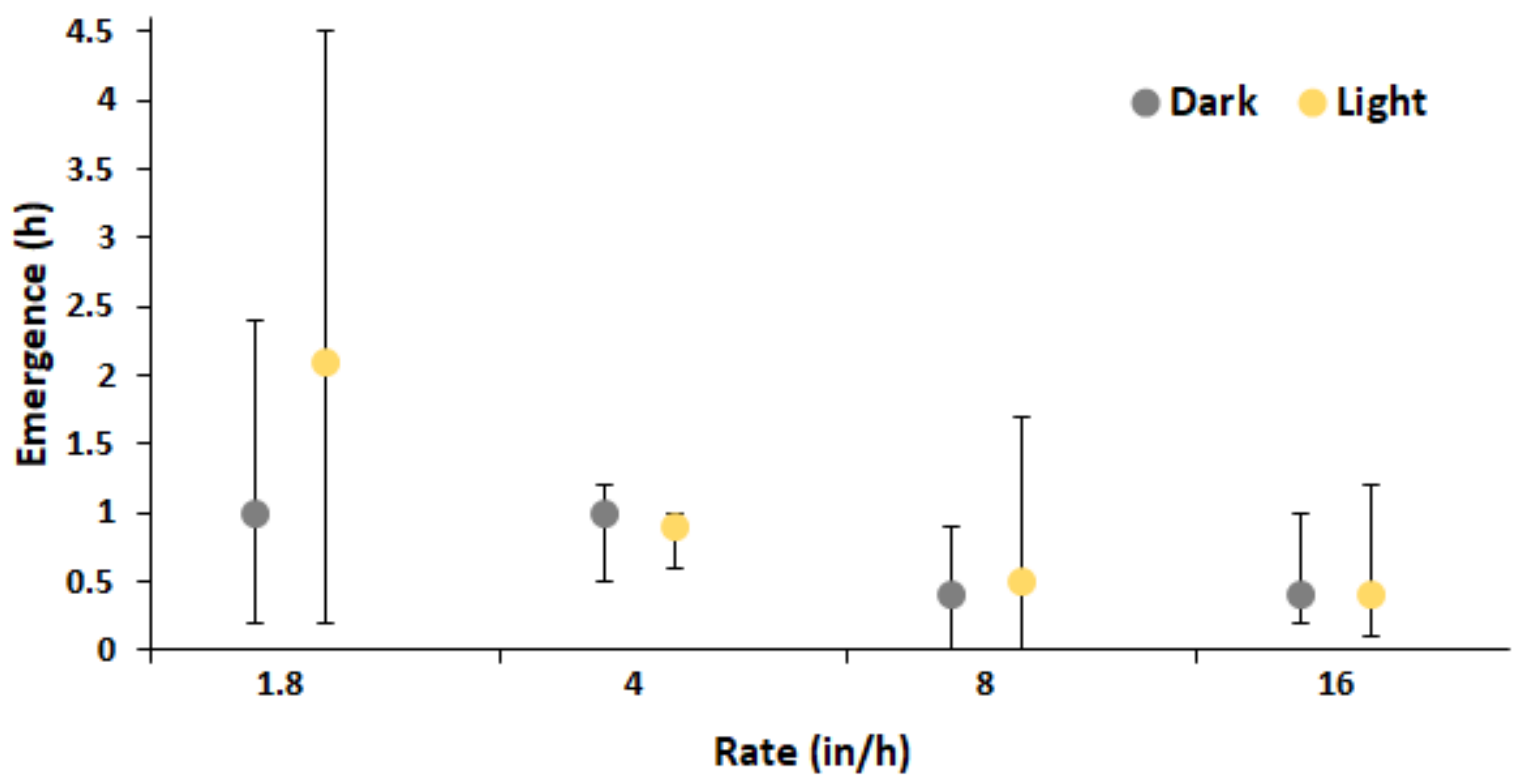

Figure 6. Graph showing median (filled circles) and minimum and maximum (at lower and upper extents of lines) time to emerge from sediment for larval lamprey exposed to dewatering at four dewatering rates and dark and light conditions. (h, hour; inch per hour, in/h)

Most larvae were recovered burrowed in the sediment at the end of a trial and those found on the surface of the sediment were predominantly in tank sections 2 and 3. Overall, 14.7 percent of larvae were on the surface of the sediment after the 1-h waiting period following dewatering. Of these, 88.6 percent were in tank sections 2 (28 of 44) and 3 (11 of 44). There were no large differences across the 10 study groups, with the exception that $1-\mathrm{L}$ did not have any larvae on the surface. The 1-in/h rate had the lowest number of larvae on the surface (9.1 percent) and the 16-in/h rate had the highest (34.1 percent), but this result was not consistent in the intermediate rates. The 1.8 -in/h rate had the second highest total number of fish on the surface ( 22.7 percent), followed by $4 \mathrm{in} / \mathrm{h}$ (18.2 percent) and $8 \mathrm{in} / \mathrm{h}$ (15.9 percent). When rates were combined, the dark and light conditions had similar numbers of larvae on the surface at the end of a trial: 54.5 percent for dark groups and 45.5 percent for light groups.

\section{Movement Rates}

Movement rates were based on 62 larvae with one observed movement, 34 fish with two movements, and 7 fish with three movements. Larvae in the small size category ranged from 45 to $68 \mathrm{~mm}$ TL and large larvae ranged from 87 to $115 \mathrm{~mm}$ TL. Larvae in the large size category were significantly bigger than fish in the small size category $(\mathrm{F}=172.9, \mathrm{df}=3, p<0.001)$, but 
within each size class the TLs in the dark and light groups were comparable. The mean TLs of small fish with dark $(55.0 \pm 3.7 \mathrm{~mm})$ and light $(56.6 \pm 6.4 \mathrm{~mm})$ movements were not significantly different. Similarly, for the large fish, the TLs were dark, 96.0 $\pm 9.0 \mathrm{~mm}$, and light, 101.1 \pm 9.5 $\mathrm{mm}$. When all groups were combined, the mean distance traveled for the first movement was $51.8 \mathrm{~cm}(\mathrm{SD}, 30.1)$; distance was smaller for the second $(20.7 \pm 13.4 \mathrm{~cm})$ and third $(15.7 \pm 7.8$ $\mathrm{cm})$ movements.

Lamprey had limited lateral movement as they moved vertically down the slope in the tank, and distance decreased with subsequent movements. In the first movement, 59.7 percent of larvae ended their movement in the same lane as they started. Each of the three lanes that made up the total width of the tank was $10.2 \mathrm{~cm}$ wide, so this group of fish had less than $10.2 \mathrm{~cm}$ of lateral movement. A smaller group of fish (37.1 percent) ended their first movement in a different lane than the one in which they started, and 3.2 percent of the first movements involved traversing two lanes. Fish observed making a second or third movement showed less lateral movement than in their first movement. The majority ( 85.3 percent) of the second movements started and ended in the same lane, and 14.7 percent involved traversing an adjacent lane. Only seven fish made a third movement, with 71.4 percent staying in one lane and 28.6 percent moving laterally to an adjacent lane.

Large fish moved faster than small fish, and differences in movement rate based on light condition were significant only for large fish. We compared rates for each movement among the four study groups: small fish during darkness (S-D), small fish during light (S-L), large fish during darkness (L-D), and large fish during light (L-L). Mean rates for the first movement were significantly different among the four groups (fig. 7; $\mathrm{F}=5.21, \mathrm{df}=3, p<0.01$ ), with the highest rate for L-L. There were no significant differences in mean rate among S-D, S-L, and L-D. For small fish, there was no significant difference between the movement rates under dark and light conditions (fig. 7). For large fish, the movement rate was significantly faster during light conditions. For the second movement, the comparison among groups showed significant differences $(\mathrm{F}=10.92, \mathrm{df}=3, p<0.001)$ similar to those for the first movement (fig. 7$)$. The mean rate for L-L was significantly higher than that for any other group, including L-D. For small fish, there was no significant difference between rates for dark and light conditions (fig. 7). Small fish had movement rates that were not significantly different from those of the large fish under dark conditions for both the first and second movements (fig. 7). As a result of small sample size (seven fish), no statistical comparisons were made for the third movements; however, as for the first and second movements, the L-L group had the highest rate (fig. 7). 


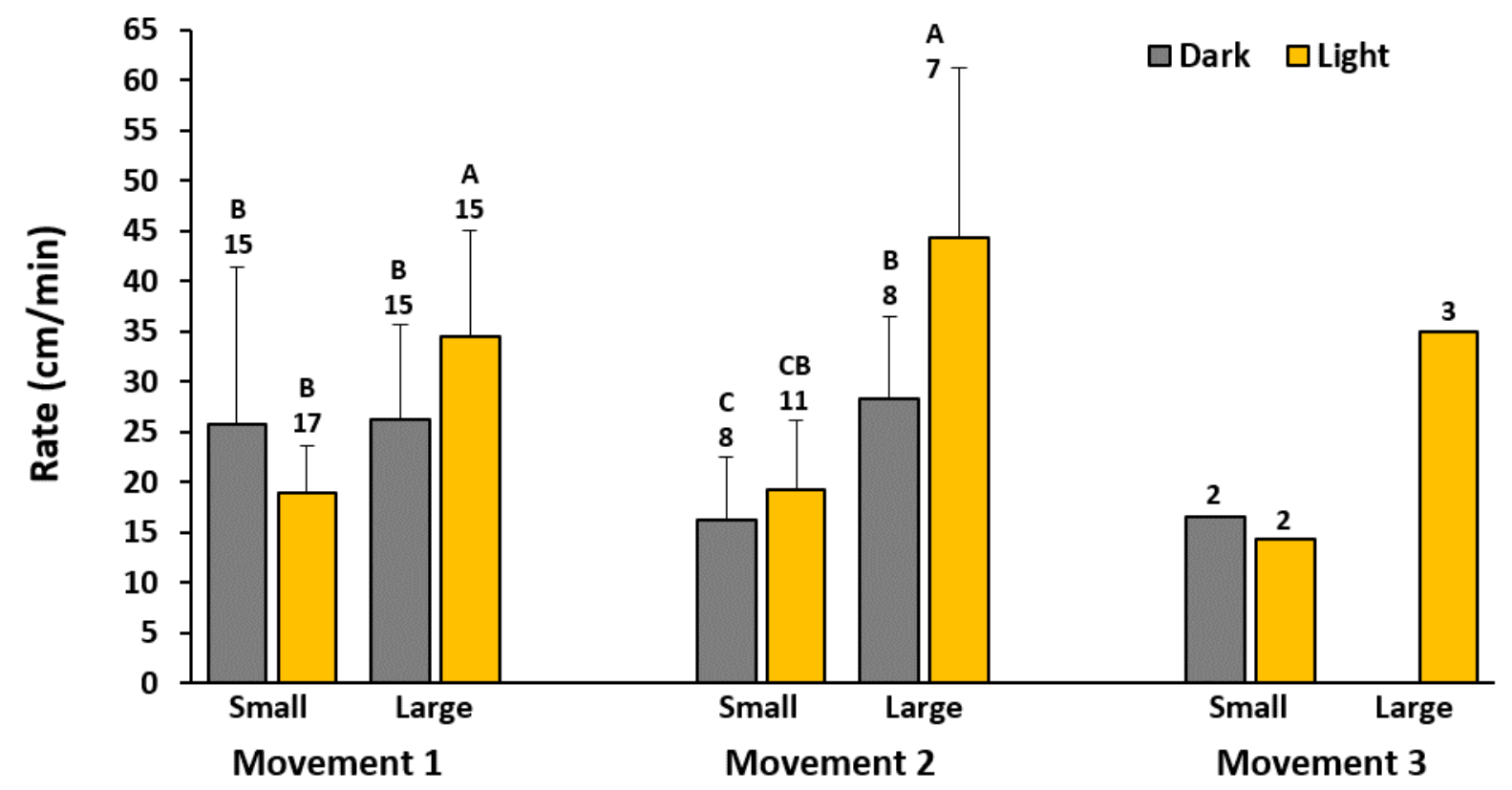

Figure 7. Graph showing movement rate for larval lamprey by size category and movement number. Error bars are the standard deviation and numbers are the sample sizes. Letters are Duncan's Multiple Range Test groupings for movements 1 and 2 , and bars without letters in common are statistically different at alpha $=0.05 .(\mathrm{cm} / \mathrm{min}$, centimeters per minute $)$

Larvae in all study groups maintained similar movement rates for their first and second movements, with no significant differences. For example, S-L had a mean rate of $19.0 \mathrm{~cm} / \mathrm{min}$ for the first movement and $19.3 \mathrm{~cm} / \mathrm{min}$ for the second (fig. 7 ; $\mathrm{t}=0.12, p=0.91$ ), and L-D had a mean rate of $26.3 \mathrm{~cm} / \mathrm{min}$ for the first movement and $28.3 \mathrm{~cm} / \mathrm{min}$ for the second $(\mathrm{t}=0.48$. $p=0.64$ ). The groups with the largest differences were S-D (difference of $9.4 \mathrm{~cm} / \mathrm{min} ; \mathrm{t}=1.51$, $p=0.14$ ) and $\mathrm{L}-\mathrm{L}$ (difference of $9.9 \mathrm{~cm} / \mathrm{min}, \mathrm{t}=1.59, p=0.13$ ).

\section{Repeated Dewatering and Rewatering Trials}

Each trial of repeated dewatering and rewatering required 4 days to execute (fig. 8). The 1 -in/ $\mathrm{h}$ trials were challenging to implement because the time to dewater $(15.4 \mathrm{~h})$ exceeded the available light $(13.3 \mathrm{~h})$ and dark $(10.7 \mathrm{~h})$ periods each day during our study period. On the basis of past experience with larvae in this test system (see Liedtke and others, 2015), fish tend to begin emerging from the sediment shortly after the surface of the sediment in the tube is dewatered. Trial timing was implemented so this period of potential emergence met the target light condition for the trial. On the basis of this priority, however, the 1-h waiting period at the end of each round of dewatering as well as the rewatering period occurred in the opposite (nontarget) light condition. For example, the 1-h waiting period for the 1-D trials started at 8:15 a.m. and rewatering began at 9:15 a.m. (fig. 8). Rewatering was conducted at a rate of $2 \mathrm{in} / \mathrm{h}$ for all trials, requiring $7.7 \mathrm{~h}$ to refill the tanks. The 16 -in/h trials were executed with the dewatering (58 min), 1-h wait, and rewatering events occurring within the target light condition (fig. 8).

Between rounds of dewatering for the 16 -in/h trials, the tanks were full of water for approximately $14.3 \mathrm{~h}$, as we waited for the next target light period (fig. 8). 

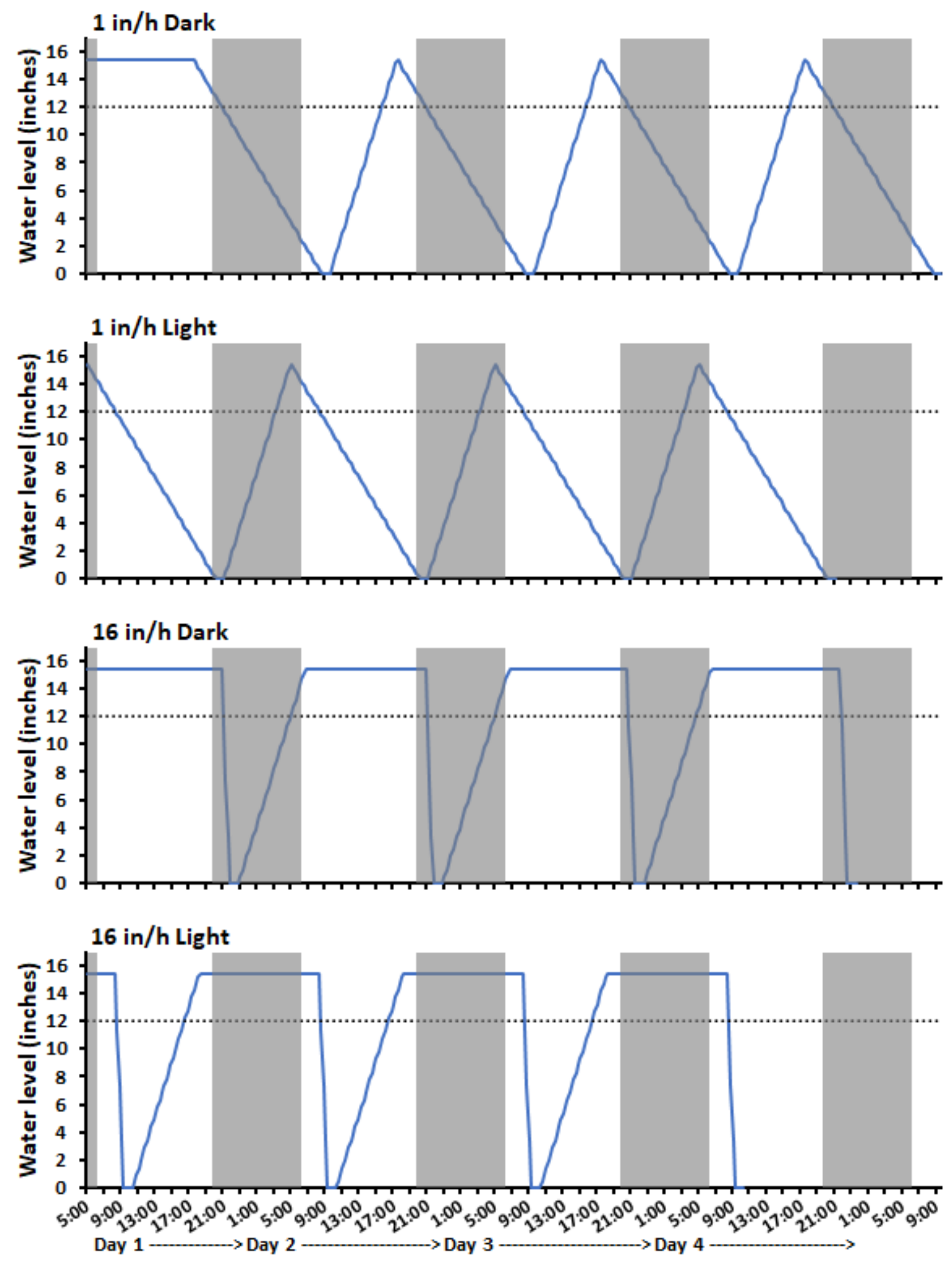

Figure 8. Graphs showing the summary of the repeated dewatering and rewatering trials for two dewatering rates and dark and light conditions, by time. Each trial was conducted over 4 days, with one dewatering event occurring each day. Blue lines indicate water level and shaded areas indicate periods of darkness. Dashed lines represent the level of substrate in the tubes. (in/h, inches per hour) 
Larval size was similar across groups in both the small and large size categories. Small fish ranged from 35 to $72 \mathrm{~mm}$ TL and the mean TLs were not significantly different among the four study groups and controls $(\mathrm{F}=1.20, \mathrm{df}=4, p=0.33$; table 4$)$. Larvae in the large category ranged from 84 to $119 \mathrm{~mm}$ TL and were not significantly different among the study groups $(\mathrm{F}=1.60, \mathrm{df}=4, p=0.20 ;$ table 4$)$.

Table 4. Summary of small and large larval lamprey size categories used in repeated dewatering and rewatering trials, including the number of fish and mean total length by group.

[Group names are a combination of dewatering rate ( 1 or 16 inches per hour) and dark (D) or light (L) conditions; mm, millimeters; SD, standard deviation]

\begin{tabular}{cccccc}
\hline & \multicolumn{3}{c}{ Small } & & \multicolumn{2}{c}{ Large } \\
\cline { 2 - 3 } \cline { 5 - 6 } Group & Number of fish & $\begin{array}{c}\text { Mean total length } \\
(\mathbf{m m})(\mathbf{S D})\end{array}$ & & Number of fish & $\begin{array}{c}\text { Mean total length } \\
(\mathbf{m m})(\text { SD) }\end{array}$ \\
\hline $1-\mathrm{D}$ & 7 & $57.8(7.2)$ & & 7 & $100.1(6.5)$ \\
$1-\mathrm{L}$ & 7 & $51.9(7.7)$ & & 7 & $95.5(8.3)$ \\
$16-\mathrm{D}$ & 7 & $57.9(13.7)$ & & 7 & $103.1(13.7)$ \\
$16-\mathrm{L}$ & 7 & $49.6(6.3)$ & & 7 & $97.3(9.8)$ \\
Control & 8 & $54.4(6.6)$ & & 8 & $107.0(9.7)$ \\
\hline
\end{tabular}

\section{Individual Fish Response}

The most common individual fish response to repeated dewatering and rewatering for all study groups was to remain burrowed through all four rounds, and there were differences in response between small and large larvae. Of the small larvae in both 1-D and 1-L, four of seven fish (57.1 percent) remained burrowed for four rounds and three of seven fish (42.9 percent) emerged during at least one round of dewatering (fig. 9). The situation was reversed for small fish in the 16-D and 16-L trials; 42.9 percent (three of seven) remained burrowed and 57.1 percent (four of seven) emerged for at least one round. The three small fish that emerged in both the 1-D and 1-L groups (six total fish) all died (fig. 9). There were two additional mortalitiesone fish in 1-L (fish 11) that remained burrowed for four rounds was dead at the end of round 4 , and one fish in 16-L that emerged in rounds 1 and 2 was dead at the end of round 2 . Another fish in 16-L (fish 28) emerged in round 1 and was lethargic, with mild hemorrhaging after it was recovered at the end of round 4 . Overall for small larvae, when all groups were combined, 14 fish emerged, and of those, 8 died and 1 was lethargic. The 1 -in/h rate had seven of the eight mortalities, split about equally between 1-D (three fish) and 1-L (four fish). All but one fish that died emerged from the sediment at some point during the four rounds of dewatering. There were no mortalities after the first round, but at least one fish died after rounds 2 through 4 (fig. 9). Within the small size category, the mean TL of fish that emerged $(57.3 \pm 9.7 \mathrm{~mm})$ was not significantly different from the mean TL of fish that remained burrowed $(51.1 \pm 8.2 \mathrm{~mm})(\mathrm{t}=1.85$, $p=0.08)$. Comparison of the mean TL of fish that emerged and died $(\mathrm{n}=7,53.1 \pm 5.3 \mathrm{~mm})$ and those that emerged and lived $(\mathrm{n}=7,49.0 \pm 10.4 \mathrm{~mm})$ showed no significant difference $(\mathrm{t}=0.94$, $p=0.37$ ). Large larvae responded differently to repeated dewatering and rewatering. Large larvae predominantly remained burrowed in all four rounds and did not experience any mortality (fig. 9). None of the large fish emerged for more than a single round, and emergence occurred only in rounds 1 and 2 (fig. 9). In control trials, all larvae (both small and large) remained burrowed and 
there were no mortalities. The highest percent emergence for a single round of dewatering across study groups and fish size categories was 42.9 percent (fig. 9). For small larvae, the most common percent emergence was 28.6 percent ( 7 of 16 events) and for large larvae the most common percent emergence was 0 percent (12 of 16 events) (fig. 9). Overall, 50.0 percent of small larvae and 27.3 percent of large larvae emerged, for a combined group total emergence of 20 fish or 35.7 percent. 

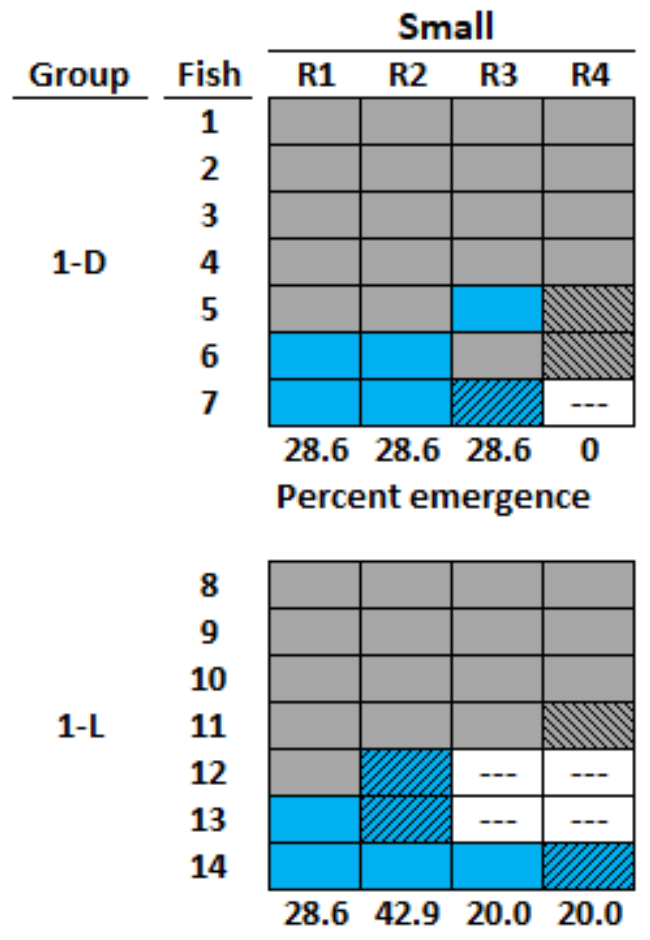

Percent emergence

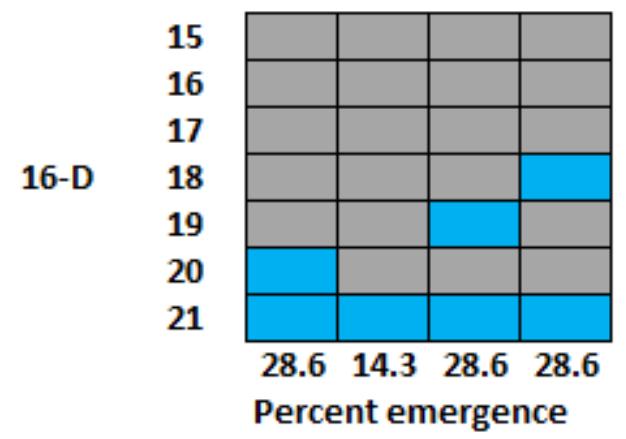

$16-\mathrm{L}$

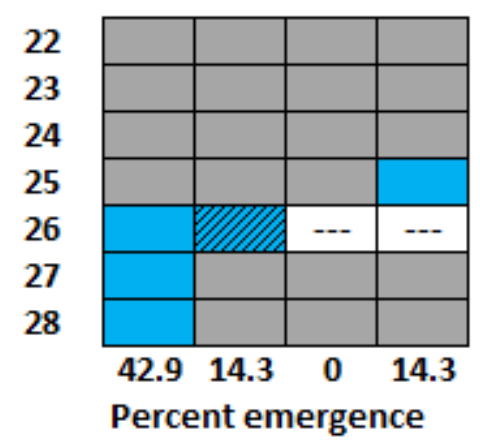

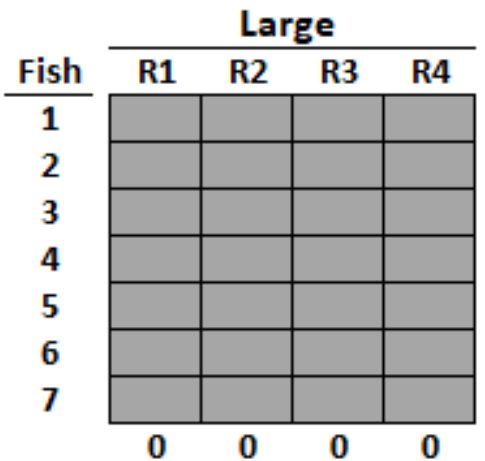

Percent emergence
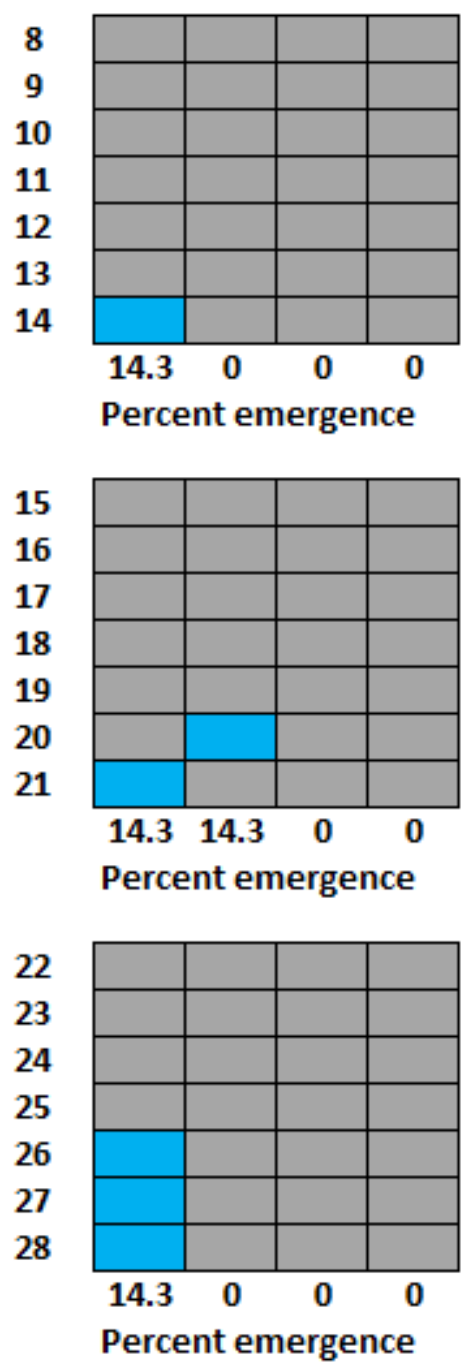

Figure 9. Graphs showing individual fish responses and percent emergence for larval lamprey exposed to repeated dewatering and rewatering trials with two dewatering rates and dark and light conditions. Each trial included four rounds (R1-R4) of dewatering, each followed by a period of rewatering. Group names are a combination of dewatering rate ( 1 or 16 inches per hour) and light condition (dark or light, D or L). Small and large larvae are depicted separately. 
Larvae emerged more quickly as the number of dewatering events increased. Emergence timing was not observed for all emergence events so sample sizes were generally low (1-5 fish per group and dewatering round). The mean time to emerge after the surface of the sediment in the tube was dewatered, when all four groups were combined, was $42 \mathrm{~min}$ in round 1 (14 fish), $16 \mathrm{~min}$ in round 2 (5 fish), $11 \mathrm{~min}$ in round 3 ( 3 fish), and $8 \mathrm{~min}$ in round 4 (3 fish). Each individual group showed a similar pattern. Mean emergence time for the 1-L group gradually decreased from round $1(51 \mathrm{~min})$ to round $3(17 \mathrm{~min})$. In round 4, the one fish that emerged did so about $1 \mathrm{~h}$ prior to dewatering of the surface of the sediment. There were nine emergence events for 1-L, five of which involved larvae emerging and reburrowing during the active dewatering phase, prior to the 1-h waiting period. For 1-D, there were seven emergence events and in two of the events the fish reburrowed. Reburrowing was observed during all four rounds of dewatering (combining 1-D and 1-L), and all larvae observed to emerge and reburrow were in the small size category. One small fish in 1-L emerged during all four rounds of dewatering, but never reburrowed. Emergence timing for this fish decreased from 44 min after the surface was exposed in the first round to $17 \mathrm{~min}$ in the third round. Another small fish in 1-L emerged in rounds 1,3 , and 4 and reburrowed each time. Two small fish in 1-L emerged during the first round, reburrowed, and then did not emerge for any subsequent dewatering events. No fish were documented to emerge and reburrow in the 16-in/h groups. In 16-D, round 1 mean time to emerge was $35 \mathrm{~min}$, compared to $8 \mathrm{~min}$ in round 4 . Timing was similar for 16-L, for which mean time to emerge decreased from $38 \mathrm{~min}$ in round 1 to $10 \mathrm{~min}$ in round 4. One small fish in 16-D emerged during all four rounds, with similar emergence timing: 9, 8, 14, and 8 min (rounds $1-4$, respectively) after the surface of the sediment in the tubes was exposed. When all groups and rounds of dewatering were combined, the overall mean time to emerge was $29 \min$ (25 fish) and ranged from $1 \mathrm{~min}$ to $2 \mathrm{~h}$ after the surface of the sediment was dewatered.

\section{Availability for Salvage}

The repeated dewatering and rewatering approach did not make many more fish available for salvage compared to a single dewatering event. If we assume that fish that emerged during the first round of dewatering were salvaged by removing them from the surface of the sediment, we can assess the potential for additional larval salvage during subsequent rounds of dewatering. In this way we compared the number of fish available for salvage during repeated dewatering and rewatering to the number available during a single dewatering event. There were 14 fish in each group, including 7 fish in each size category. In the 1-D trials, two fish could have been salvaged after round 1, and one additional fish could have been salvaged after round 3 (fig. 9). All of the salvaged fish would have been small because none of the large fish emerged. For 1-L, three larvae could have been salvaged after round 1 , and one additional fish emerged after round 2. A few more fish were available for salvage during the 16 -in $/ \mathrm{h}$ trials compared to the 1 -in $/ \mathrm{h}$ trials. In 16-D, three fish could have been salvaged after round 1 , and three more were available in subsequent rounds. The highest potential salvage rate was in 16-L; six fish emerged after

round 1 , and one more after round 4 , resulting in seven fish (50.0 percent) available for salvage. Across all groups and rounds, 20 larvae emerged, 14 (70.0 percent) in round 1 and six (30.0 percent) after round $1-10.0$ percent in each of rounds 2 through 4 (fig. 9). 


\section{Vertical Distribution}

Larvae burrowed deeper during the 1 -in/h trials than the 16 -in $/ \mathrm{h}$ trials, and few fish were deeper than about $23 \mathrm{~cm}$. The highest concentration of larvae was in stratum 3 for 1-D (50.0 percent) and stratum 1 for 1-L (50.0 percent) (table 5). The mean depth stratum was 2.1 for 1-D and 2.0 for 1-L. In the 16-in/h trials, most larvae were in the uppermost stratum, 57.1 percent for 16-D and 80.0 percent for 16-L (table 5). The mean depth stratum was 1.6 for 16-D and 1.3 for 16-L. Overall, when all study groups were combined, the mean depth stratum was 1.8 and the highest concentration of larvae was in stratum 1 (55.7 percent). The controls, which did not experience dewatering, had a similar distribution to the overall treatment group, with 50.0 percent of fish in the first stratum, no fish deeper than the third stratum, and a mean stratum of 1.6 (table 5). Only two fish burrowed in stratum 4 (deeper than $22.8 \mathrm{~cm}$ ), and both occurrences were during light conditions, one fish in 1-L and one fish in 16-L.

Table 5. Vertical distribution of larval lamprey by group and depth strata. Control fish were not dewatered. For the overall total and each group individually, the stratum containing the highest percentage of fish is shown in bold.

[Group names are a combination of dewatering rate (1 or 16 inches per hour) and dark (D) or light (L) conditions; $\mathrm{cm}$, centimeters]

\begin{tabular}{cccccccc}
\hline Strata number & \multicolumn{1}{c}{ Depth strata } & Control & 1-D & 1-L & 16-D & 16-L & Total \\
\hline 1 & $\begin{array}{c}\text { Fish 0-7.6 cm deep } \\
\text { (percent) }\end{array}$ & $\mathbf{5 0 . 0}$ & 37.5 & $\mathbf{5 0 . 0}$ & $\mathbf{5 7 . 1}$ & $\mathbf{8 0 . 0}$ & $\mathbf{5 5 . 7}$ \\
2 & $\begin{array}{l}\text { Fish 7.6-15.2 cm deep } \\
\text { (percent) }\end{array}$ & 37.5 & 12.5 & 6.3 & 28.6 & 13.3 & 14.8 \\
3 & $\begin{array}{l}\text { Fish } 15.2-22.8 \mathrm{~cm} \text { deep } \\
\text { (percent) }\end{array}$ & 12.5 & $\mathbf{5 0 . 0}$ & 37.5 & 14.3 & 0 & 26.2 \\
4 & $\begin{array}{l}\text { Fish } 22.8-30.5 \mathrm{~cm} \text { deep } \\
\text { (percent) }\end{array}$ & 0 & 0 & 6.3 & 0 & 6.7 & 3.3 \\
$\begin{array}{c}\text { Mean depth } \\
\text { stratum }\end{array}$ & & 1.6 & 2.1 & 2.0 & 1.6 & 1.3 & 1.8 \\
\hline
\end{tabular}

Large larvae burrowed deeper than small larvae. Small larvae were most concentrated in the uppermost stratum (83.7 percent), with a mean stratum of 1.3 (table 6). Large fish were concentrated in stratum 3 (43.3 percent), with a mean stratum of 2.3. In control trials, small fish were most common in stratum 1 (62.5 percent) and large fish were equally common in strata 1 and 2 (37.5 percent) (table 6). The mean depth stratum for small control fish (1.4) was similar to that for the small treatment group (1.3), but larger fish exposed to dewatering tended to be deeper (mean stratum=2.3) than those in the control group (mean stratum=1.9) (table 6). 
Table 6. Vertical distribution of larval lamprey by control and treatment group, small and large larvae, and depth strata. The treatment columns represent two dewatering rates (1 and 16 inches per hour) and two light conditions (dark and light), pooled. Control fish were not dewatered. For each group category, the stratum containing the highest percentage of fish is shown in bold.

[cm, centimeters]

\begin{tabular}{|c|c|c|c|c|c|}
\hline \multirow{2}{*}{ Stratum number } & \multirow{2}{*}{ Depth stratum } & \multicolumn{2}{|c|}{ Control } & \multicolumn{2}{|c|}{ Treatment } \\
\hline & & Small & Large & Small & Large \\
\hline 1 & Fish 0-7.6 cm deep (percent) & 62.5 & 37.5 & 83.7 & 26.7 \\
\hline 2 & Fish 7.6-15.2 cm deep (percent) & 37.5 & 37.5 & 6.5 & 23.3 \\
\hline 3 & Fish $15.2-22.8 \mathrm{~cm}$ deep (percent) & 0 & 25.0 & 9.7 & 43.3 \\
\hline 4 & Fish $22.8-30.5 \mathrm{~cm}$ deep (percent) & 0 & 0 & 0 & 6.7 \\
\hline Mean depth stratum & & 1.4 & 1.9 & 1.3 & 2.3 \\
\hline Number of fish & & 8 & 8 & 31 & 30 \\
\hline
\end{tabular}

The second dewatering event resulted in greater mean burrowing depth than the first event, but trends after the second event were less clear. The overall mean depth stratum increased from 1.6 after round 1 of dewatering to 1.9 after the second round (table 7). Mean depth was similar between round 2 and round 3 and became shallower after round 4 (table 7). The overall trend was affected mainly by the small fish because the mean depth for large fish was consistent across the four rounds of dewatering (table 7).

Table 7. Vertical distribution of larval lamprey, expressed as mean depth strata, by small and large larvae and dewatering round during the repeated dewatering and rewatering trials. Depth stratum 1 was 0 $7.6 \mathrm{~cm}$, stratum 2 was $7.6-15.2 \mathrm{~cm}$, stratum 3 was $15.2-22.8 \mathrm{~cm}$, and stratum 4 was $22.8-30.5 \mathrm{~cm}$. [Numbers in parentheses are the number of fish tested in each round; $\mathrm{cm}$, centimeters]

\begin{tabular}{cllll}
\hline Fish size & Round 1 & Round 2 & Round 3 & Round 4 \\
\hline Small & $1.0(8)$ & $1.6(8)$ & $1.4(7)$ & $1.0(8)$ \\
Large & $2.3(8)$ & $2.3(8)$ & $2.3(7)$ & $2.4(7)$ \\
Total & $1.6(16)$ & $1.9(16)$ & $2.0(14)$ & $1.7(15)$ \\
\hline
\end{tabular}

There were three mortalities in the vertical distribution tubes for the 16-in/h groups. There were no mortalities for the 1 -in/h groups. One large fish (6.3 percent) died in 16-L in round 2, after emerging in round 1. Two fish (12.5 percent) died in 16-D, one large fish and one small fish. The small fish was on the surface in round 1 and dead at the end of round 2 . The large fish was burrowed in round 1, on the surface for round 2, and dead at the end of round 3. Although mortality was also observed in the primary tubes for the repeated dewatering and rewatering trials (see individual fish response, above), all mortalities were small fish. In the tubes used to assess vertical distribution, however, two of the three mortality events were for large fish. 


\section{Discussion}

None of the tested dewatering rates offered enough protection for larval lamprey to be considered an effective stand-alone conservation action. Our working hypothesis was that the slower dewatering rates, potentially combined with dark conditions, might allow most larvae to regain access to water, limiting stranding to perhaps 20 to 30 percent of the fish. Our tests found, instead, that all rates resulted in the stranding of high proportions of fish, and there was no evidence that dewatering during dark conditions was more protective than dewatering during light conditions. The slowest rate we tested had the lowest stranding rate, leaving about 77 to 80 percent of the larvae in areas without access to water. Faster rates resulted in more fish being stranded. Reducing the number of lamprey stranded during a dewatering event would help protect larvae, but because the minimum stranding rate was 77 percent, the protective effect was minimal. On the basis of the range of rates we tested, it seems likely that even rates less than 1 in $/ \mathrm{h}$ may result in the stranding of high proportions of larvae. For example, the $0.8-\mathrm{in} / \mathrm{h}$ difference between the 1-in/h and 1.8-in/h dewatering rates resulted in differences in stranding rates of about 21 percent in the dark and 13 percent in the light. If we apply the same percent differences to a hypothetical dewatering rate of $0.2 \mathrm{in} / \mathrm{h}(0.8 \mathrm{in} / \mathrm{h}$ less than $1 \mathrm{in} / \mathrm{h})$, we would predict stranding rates of 64 to 67 percent. Hypothetically, fewer larvae would be stranded, but the dewatering rate would not be protective for most of the fish. Previous reported observations of larval and juvenile lamprey in the laboratory and in the field indicate that they have increased activity at night (Moursund and others, 2000; Goodman and others, 2015; Moser and others, 2015). We hypothesized on the basis of this increased activity that dewatering under dark conditions would result in fewer larvae being stranded. Our findings, however did not support this hypothesis. At each dewatering rate, the stranding rate for the dark group was the same as, or higher than, the rate for the light group. Although this study did not identify an "optimal" dewatering rate and light condition, it confirmed that lower dewatering rates are more protective than faster rates. This information is useful to guide the conditions under which future dewatering events are conducted, as dewatering locations are highly variable in terms of larval densities, shoreline slope, sediment type, and how long habitat may be dewatered.

Most larvae were classified as stranded in the movement trials because they never emerged from the sediment in tank section 1, where they were initially stocked. That is, they showed no apparent response to dewatering. Larvae may have moved within the sediment, perhaps to deeper locations as dewatering progressed, but our test system did not allow us to monitor this behavior rigorously. Overall, about 20 to 50 percent of fish from each group responded by emerging from the sediment in tank section 1 and initiating movement downslope, attempting to regain access to water. Most groups ( 7 of 10) had no more than 30 percent of larvae emerge and initiate movement. The 1-in/h groups had the lowest stranding rates, in large part because they had the highest proportion of larvae that left section 1 (43-50 percent). When all the evidence is taken together, it seems that dewatering rate is only one component of stranding. We need to better understand the factors that affect larval emergence during a dewatering event because emerging is the first action in the chain of events that could result in larvae being safe. After a fish emerges, it can either self-rescue by moving downslope and regaining access to the water or be recovered from the surface of the sediment during typical salvage operations. Once larvae emerge, the dewatering rate affects the likelihood that they can self-rescue, as slower rates allow them to traverse less exposed substrate and more time to regain access to the water as it retreats. An improved understanding of the cues that prompt larvae to 
emerge, combined with the ability to manage dewatering rates, would be useful to guide future dewatering events to minimize adverse effects to lamprey.

Larval lamprey moved, over short distances, at rates that exceeded the fastest dewatering rate we tested. We measured movement rates to better understand whether the risk of stranding was due to the inability of larvae to travel over the sediment fast enough to match the pace of the receding water. The fastest dewatering rate we tested, $16 \mathrm{in} / \mathrm{h}$, resulted in water receding over the surface of the sediment at a rate of $6.8 \mathrm{~cm} / \mathrm{min}$. The mean movement rates for groups of lamprey ranged from 19.0 to $44.4 \mathrm{~cm} / \mathrm{min}$. Only the slowest movement rate we measured, $6.6 \mathrm{~cm} / \mathrm{min}$, for an individual lamprey, was slower than the fastest dewatering rate. This finding indicates that the high stranding rates we observed were not due simply to the inability of larvae to keep pace with the receding water but must also include factors such as the proportion of fish that emerged and initiated movement. In our test system, larvae would need to travel about $150 \mathrm{~cm}$ from the lower end of tank section 1 to the uppermost margin of the water at the bottom of the tank. Lamprey in our trials moved an average of about $52 \mathrm{~cm}$, slightly more than one-third the total distance from where they were placed to where they could access water on the surface. It is unclear how long larvae may be able to sustain the movement rates we measured, but based on observations during these trials, as well as previous testing in the same tank (Liedtke and others, 2015), we would estimate that, depending on size, they may tire quickly. We did not measure movement rates in our previous work, but we found that small larvae would quickly become exhausted attempting to move over the surface of the sediment, especially if they encountered any depressions or ridges (Liedtke and others, 2015). It is important to note as well that on the basis of our procedures our reported rates may be biased high. Larvae were placed on the surface of the sediment in tank section 1 to begin tests of movement rate. Our goal was to monitor rates of larvae that were burrowed in the sediment, volitionally emerged, and then traveled down the slope toward the water. Early tests, however, forced us to change our approach, as very few fish emerged after they were burrowed. By placing fish on the surface of the sediment, larvae could begin moving immediately and did not expend any energy emerging from a burrow. In natural settings, lamprey burrowed deeply in the sediment or in sediment that compacts easily during dewatering would likely expend substantial energy to emerge. The comparisons of movement rate by light condition could also be affected by our procedure of placing larvae on the surface. We found the fastest movement rates during light conditions, possibly because the larvae actively sought a location in which to burrow to avoid the light. Ideally, movement rates would be measured under variable light conditions following volitional emergence.

Repeated dewatering and rewatering did not result in high proportions of larvae emerging from the sediment. The rationale behind testing this dewatering approach was based on field observations that additional larvae emerged following a dewatering event when it was rewatered overnight through seepage. Previous laboratory evaluations of larval responses to dewatering showed that about 50 percent of lamprey emerged shortly after the surface of the sediment was dewatered (Liedtke and others, 2015). The hypothesis was that about 50 percent of larvae would emerge in the first round of dewatering, making them accessible for salvage or self-rescue. Using this half-life approach for four rounds of dewatering, we would expect to have less than 10 percent of the fish remaining in the dewatered habitat. In the trials, however, the highest percent emergence for a single round of dewatering was about 43 percent for small fish and about 14 percent for large fish. The most common response, especially for large fish, was to remain burrowed for each of the four rounds of dewatering. Of the fish that emerged, 70 percent did so in the first round of dewatering. Each subsequent round added about 10 percent more fish. 
Neither the rate $(1 \mathrm{in} / \mathrm{h}$ compared to $16 \mathrm{in} / \mathrm{h})$ nor the light condition had a large effect on the percentage of larvae that emerged. Using several rounds of dewatering with rewatering between them was not an effective approach to improve the opportunity for salvage or self-rescue.

Few larvae burrowed deeper than $23 \mathrm{~cm}$ and vertical distribution was affected by fish size, dewatering rate, and the number of dewatering events. About 70 percent of larvae burrowed in the top two strata of our test system, which was less than about $15 \mathrm{~cm}$. Adding one stratum, to a depth of about $23 \mathrm{~cm}$, accounted for about 97 percent of the fish. Fish size affected vertical distribution, with large larvae consistently found deeper than small larvae, both following a dewatering event and when no dewatering occurred. Mean depth stratum was slightly greater under dark conditions than light conditions, but the dewatering rate had a larger effect. Larvae were deeper during the 1-in/h trials than during the 16 -in/h trials. It took about $15 \mathrm{~h}$ to completely dewater the tank holding the tubes using the slow rate, allowing larvae time to detect changing conditions and respond, whereas with the fast rate, the tank was totally dewatered in less than an hour $(0.96 \mathrm{~h})$. With conditions changing so quickly, it may be that larvae did not alter burrow depth because they did not have time to respond. During the repeated dewatering and rewatering trials, we found that small larvae burrowed deeper after the second round of dewatering than after the first round. After the second round, however, the trends were not consistent. Relative to our past work, larvae in these tests were burrowed deeper. Previously we observed that no larvae burrowed deeper than $15.2 \mathrm{~cm}$, and the largest proportion of fish was shallower than about $8 \mathrm{~cm}$ (Liedtke and others, 2015). These trends applied to fish that were dewatered as well as controls that did not experience dewatering (Liedtke and others, 2015). Differences between the 2015 study and the current study include (1) the sediment used, (2) larval size, and (3) larval source. In our initial work in 2015, we used a commercial sand sieved for consistent size (median grain size 0.378 millimeters [mm], medium sand). It was selected because we used it for our lamprey culture and it had performed well in that capacity. We noted, however, that the sand quickly became compacted and hard following dewatering, basically eliminating the option for lamprey to reburrow (Liedtke and others, 2015). The sediment used in 2019 was from a field setting where larval lamprey had been collected previously. It was slightly coarser (median grain size $0.445 \mathrm{~mm}$, medium sand), with a smaller proportion of fine sand or smaller particles compared to the 2015 sediment, which could have affected burrowing behavior or vertical distribution of larvae. Fish size was the second difference between the 2015 and 2019 studies that might have affected burrowing behavior. The mean TL of larvae in the 2015 study $(69.3 \pm 22.8 \mathrm{~mm})$ was smaller than the mean TL in $2019(79.6 \pm 26.9 \mathrm{~mm})$. Larger larvae burrow more deeply, and a 10-mm increase in length for the 2019 larvae likely affected the mean burrowing depth. Another potential factor affecting burrowing behavior was the source of larvae. In 2015, larvae used for testing had been maintained in our laboratory for several years. For the current work, larvae were collected from a field setting that experiences changing water levels and held in the laboratory for no more than 6 weeks. For ease of culture and maintenance, our laboratory holding systems provide about $5 \mathrm{~cm}$ of sand for burrowing. Perhaps burrowing behavior, especially in response to dewatering, is altered through experience, and fish in field settings are exposed to a wider range of conditions relative to those in the laboratory. We found some support for this theory in our finding that small larvae were burrowed deeper after the second round of dewatering than after the first round.

The proportion of fish that emerged from the sediment in response to dewatering was lower than that observed in previous laboratory work or in a field setting (Liedtke and others, 2015; Skalicky and others, 2019). Our 2015 evaluation of larval responses to dewatering 
reported that about 50 percent of larvae emerged, beginning shortly after the surface of the sediment was dewatered (Liedtke and others, 2015). During a field evaluation of dewatering, Skalicky and others (2019) reported the same finding, about 50-percent volitional emergence. In the present study we observed 30-percent emergence during the movement trials in the tank with a simulated shoreline at a 10-percent slope, and about 36-percent emergence during the repeated dewatering and rewatering trials conducted in tubes. In both test systems, small larvae emerged more often than large larvae. Comparisons between the 2015 and 2019 laboratory evaluations must consider the differences in sediment and fish source, as discussed previously. Emergence timing was broadly described in the 2015 study but was rigorously measured in 2019, as we thought it would be useful to guide future field investigations or salvage efforts. As for the 2015 finding, we observed that larvae generally did not emerge for a period after the surface of the sediment was exposed. Overall, the delay in emergence was about $40 \mathrm{~min}$ and the maximum time to emerge after the sediment was dewatered was $4.5 \mathrm{~h}$.

Larval size played a role in lamprey responses to dewatering, having a significant effect on emergence, movement rate, and vertical distribution. We carefully managed larval sizes for each trial and group to avoid any initial size bias. During the movement trials, larvae that emerged were significantly smaller than those that remained burrowed, a finding that matched our findings in 2015 (Liedtke and others, 2015). We could only make statistical comparisons of the size of safe as opposed to stranded larvae for the 1-in/h groups because the other dewatering rates had so few safe fish. The sizes of safe fish and stranded fish were not significantly different for 1-D, but safe larvae were significantly smaller than stranded larvae for 1-L. This difference is linked with the likelihood of emergence because most larvae classified as stranded never emerged from the sediment, which was the most common behavior for large fish, thereby increasing the mean size of stranded fish.

Movement-rate testing showed that large larvae moved at faster rates than small larvae, especially during light conditions. Small larval movement rates were statistically indistinguishable under dark and light conditions and were not significantly different from the rates of large larvae under dark conditions. Large larvae moving under light conditions, however, were significantly faster than all other groups. This difference in movement rate could translate to improved survival during dewatering events in field settings where larvae must traverse exposed sediment to regain access to water. Larval behavior during the repeated dewatering and rewatering trials was affected by size. Small fish emerged at higher rates (50-percent emergence overall) and experienced several mortalities, typically after emerging during at least one round of dewatering. Large fish emerged at lower rates (27.3 percent overall), were more limited in the timing and duration of their emergence and did not experience any mortality. Comparing availability for salvage under the repeated dewatering and rewatering approach to a traditional, single round of dewatering, very few large fish would have been salvaged.

The vertical distribution trials demonstrated that large fish were burrowed deeper than small fish, both in the control groups that did not experience dewatering and in dewatered groups. Taken together, these findings along with findings from the 2015 study highlight that small larvae are especially vulnerable to dewatering. They are more likely to emerge from the sediment, making them four times less likely to survive than larvae that remain burrowed (Liedtke and others, 2015), and they may struggle to move effectively over dewatered substrates to regain access to water. In addition, the 2015 study showed that the odds of surviving dewatering increased by a factor of 2 for every 10-mm increase in TL (Liedtke and others, 2015). It is not clear how larval size affects the choice to emerge and move along the surface toward 
water as opposed to remaining burrowed, or potentially burrowing deeper, during dewatering events in field settings. More information from field studies is needed to better understand how larvae of different sizes behave during dewatering, and how that behavior relates to survival. Combining field observations with the findings from laboratory studies will provide the best guidance for how dewatering can best be managed to reduce negative effects on larval lamprey.

Larvae were more active in the dark, but darkness did not consistently provide better outcomes than daylight. Throughout all the experiments, there were indications that larval activity increased in the dark. For example, more larvae were detected on the surface during movement trials in the dark than in those in the light. A control movement trial (no dewatering) had a larva swimming throughout the tank until the 1-h waiting period was over and lights were turned on, at which point it immediately burrowed. During the repeated dewatering and rewatering trials, we saw lamprey actively swimming at night, but during the day they remained burrowed. The increased activity, however, did not result in fewer larvae stranded in movement trials or more fish available for salvage in repeated dewatering and rewatering trials. For example, the 1 -in/h movement trials had more larvae emerge and move downslope in the dark than in the light, but more larvae were stranded in the dark trials. Light condition had no effect on movement rates for small larvae, and large larvae had significantly slower movement rates in the dark than in the light. As noted previously, however, movement-rate trials may not accurately depict larval behavior, and higher movement rates during the day may reflect a desire to find a new burrowing location and avoid the light. The vertical distribution of larvae was marginally affected by light condition, with fish found somewhat deeper in the dark. Overall, our findings are like those of other studies that report increased nighttime activity (Moursund and others, 2000; Goodman and others, 2015; Moser and others, 2015). Our previous evaluation of larval responses to dewatering was conducted exclusively during daylight (Liedtke and others, 2015); the current work, to our knowledge, is the first laboratory evaluation of response to dewatering in which movement during dark and light conditions was compared.

\section{Conclusions}

Slower dewatering rates offered some opportunity for larval lamprey to escape stranding. The best outcome was for the slowest dewatering rate $(1 \mathrm{in} / \mathrm{h})$. Although this rate left about 77 percent of the larvae stranded in areas without surface water, a slow dewatering rate used in a field setting could allow some fish to return to watered areas and prevent the 100-percent mortality that might occur with faster dewatering rates. Larval densities can be high in fluvial sediments and use of a slow dewatering rate in these areas can result in survival of large numbers of larvae. For example, Skalicky and others (2019) estimated more than 12,000 larvae in a single dewatered area (1,142 square meters) of a large reservoir, and multiple fine sediment deposits outside the study area were also dewatered. Thus, using a slow dewatering rate to allow a proportion of the larvae to escape stranding could potentially save thousands to millions of larvae in situations where larval densities are high and expansive areas are dewatered.

Larvae were more active at night, but nighttime dewatering did not result in improved outcomes for lamprey compared to daytime dewatering. Like the findings of Liedtke and others (2015), the size of larvae had a significant effect on behavior and outcomes, with small fish consistently more vulnerable to negative effects. We expected to see about 50 percent of larvae emerge from the sediment on the basis of our previous laboratory observations (Liedtke and others, 2015) and reported field observations (Skalicky and others, 2019), but overall emergence was about 30 to 36 percent. Similarly, we found larvae to be burrowed in the sediment to a depth 
of about $23 \mathrm{~cm}$ whereas our previous work documented that no larvae burrowed deeper than about $15 \mathrm{~cm}$ (Liedtke and others, 2015). New information collected during this study included emergence timing and movement rates. It has been shown that larvae generally emerge shortly after the surface of the sediment is dewatered (Liedtke and others, 2015; Skalicky and others, 2019), but this study quantified that response. We found that emergence tended to occur within about 40 minutes after the surface of the sediment was exposed. The movement rates we measured for larvae indicate that they can, at least over short distances, move over the substrate and keep pace with fast dewatering rates $(16 \mathrm{in} / \mathrm{h})$, giving them the chance to regain access to water. These findings should be useful to provide insights into how planned dewatering events can best be managed to limit adverse effects on larval lamprey.

The focus of this study was Pacific lamprey because of their declining status and cultural and ecological significance (Close and others, 2002; Wang and Schaller, 2015; Clemens and others, 2017). however, our findings can be considered for any species of lamprey, such as the sympatric Western Brook lamprey, that have strong associations with fluvial sediments and may be vulnerable to dewatering. Species-specific evaluations in the future may provide additional insights, but lacking other information, this study provides a defensible foundation.

More evaluations of larval responses to dewatering in field settings would add to the information we learned in this study. There is growing interest and momentum in this arena, but to date (2020), few studies have been conducted (Beals and Lampman, 2018; Skalicky and others, 2019). Controlled laboratory studies certainly provide insights into larval responses, but conditions in field settings are substantially more complex. In the field, dewatered larvae may be exposed to environmental conditions that exacerbate desiccation, limit their ability to traverse dewatered substrate, and expose them to predation. The combination of laboratory and field studies is a powerful approach, leveraging the control of laboratory settings and the realism of field settings. Conducting future laboratory experiments with larvae collected from the field with a limited duration of laboratory holding will best represent larval behavior in the field.

Sediment type appears to play a key role in larval behavior, and more research is needed to better understand its effect. Initially we conducted experiments using commercial sand and learned that it compacted after it was dewatered, potentially limiting larval behaviors like reborrowing (Liedtke and others, 2015). To remedy that concern, we conducted this study using sediment collected from a field location where lamprey had been collected previously. The natural sediment was an improvement, but still represents a simplified depiction of lamprey habitat in stream and river sediments. The proportion and size of the particles in a sediment (from gravel to silt and clay) are important descriptors of how sediments respond to dewatering, but the stratigraphy may also play a role. For example, a layer of silt or clay may resist dewatering, allowing water to be retained above the layer. Larger particles or large organic matter can create interstitial spaces where larvae may burrow more easily but may also desiccate more rapidly. If, like the commercial sand used in our early work, a sediment compacts quickly when dewatered, limiting the ability of larvae to reburrow, larvae that emerge may be more vulnerable to predation or desiccation if they are unable to access water. Conducting laboratory studies with sediments collected from field locations where lamprey have been observed and field studies that collect and describe the sediment components and stratigraphy at their study sites can help fill this information gap.

Following a dewatering event, larval lamprey may emerge from the sediment and attempt to move to water, or remain burrowed, possibly increasing their depth, in anticipation that the substrate will be rewatered. There are tradeoffs to consider for both strategies and little is known 
about conditions that affect this choice or which strategy grants the best survival advantage. As this study and others found that about 30 to 50 percent of larvae emerge, it seems that the dewatering rate and (or) light condition are not the only variables that must be considered. Future research ideally will focus on the cues that cause larvae to emerge from dewatered sediment. The microhabitat of each larva may affect emergence behavior. For example, if there is insufficient moisture to respire effectively, or the sediment becomes compacted and creates physical strain, larvae may emerge. We observed some larvae emerge and then, after a short period on the surface, reburrow. Were they comparing surface conditions to their burrowed microhabitat? Past experience may play a role; for example, in tidal-influenced habitats, larvae may not emerge as they anticipate rewatering. Improving our understanding of the drivers of these behaviors is critical to our ability to mitigate risks to larvae during dewatering.

\section{Acknowledgments}

This work was funded through the U.S. Fish and Wildlife Service, Portland, Oregon, Fish and Wildlife Office, as part of ongoing collaborations with the Lamprey Conservation Initiative. Field collection of lampreys was made possible through assistance from U.S. Fish and Wildlife staff at the Columbia River Fish and Wildlife Conservation Office in Vancouver, Washingtonspecifically Tim Whitesel, who coordinated the collection permit, and Judith Barksdedt, Jennifer Poirier, Brook Silver, David Hines, and Jamie Sprando, who assisted with lamprey field collection efforts. U.S. Geological Survey colleagues, Ryan Tomka, Collin Smith, Joe Warren, and Morgan Andrews., at the Columbia River Research Laboratory, Cook, Washington are gratefully acknowledged for assisting with lamprey collection as well as experimental setup and execution. Reviews of this document by Laurie Porter and Jill Hardiman are greatly appreciated.

\section{References Cited}

Beals, T., and Lampman, R., 2017 Intensive monitoring of larval/juvenile entrainment in the Yakima Subbasin, Bureau of Reclamation Contract No. R15AC00044. Confederated Tribes and Bands of the Yakima Nation, Washington, $17 \mathrm{p}$.

Clemens, B.J., Beamish, R.J., Coates, K.C., Docker, M.F., Dunham, J.B., Gray, A.E., Hess, J.E., Jolley, J.C., Lampman, R.T., McIlraith, B.J., Moser, M.L., Murauskas, J.G., Noakes, D.L.G., Schaller, H.A., Schreck, C.B., Starcevich, S.J., Streif, B., van de Wetering, S.J., Wade, J., Weitkamp, L.A., and Wyss, L.A., 2017, Conservation challenges and research needs for Pacific Lamprey in the Columbia River Basin: Fisheries, v. 42, no. 5, p. 268-280.

Close, D.A., Fitzpatrick, M., and Li, H., 2002, The ecological and cultural importance of a species at risk of extinction, Pacific lamprey: Fisheries, v. 27, no. 7, p. 19-25.

Goodman, D.H., Reid, S.B., Som, N.A., and Poytress, W.R., 2015, The punctuated seaward migration of Pacific Lamprey (Entosphenus tridentatus) - Environmental cues and implications for streamflow management: Canadian Journal of Fisheries and Aquatic Sciences, v. 72, no. 12, p. 1817-1828. [Also available at https://doi.org/10.1139/cjfas-2015-0063.]

Liedtke, T.L., Weiland, L.K., and Mesa, M.G., 2015, Vulnerability of larval lamprey to Columbia River hydropower system operations - Effects of dewatering on larval lamprey movements and survival: U.S. Geological Survey Open-File Report 2015-1157, 28 p., http://dx.doi.org/10.3133/ofr20151157. 
Moser, M.L., Jackson, A.D., Lucas, M.C., and Mueller, R.P., 2015, Behavior and potential threats to survival of migrating lamprey ammocoetes and macrophthalmia: Reviews in Fish Biology and Fisheries, v. 25, no. 1, p. 103-116. [Also available at https://doi.org/10.1007/s11160-014-9372-8.]

Moursund, R.A., Dauble, D.D., and Bleich, M.D., 2000, Effects of John Day Dam bypass screens and project operations on the behavior and survival of juvenile Pacific Lamprey (Lampetra tridentata) — Final report: Prepared by Pacific Northwest National Laboratory, Richland, Washington, for U.S. Army Corps of Engineers, Portland District, Portland, Oregon, 25 p., 2 app.

Rose, B.P., and Mesa, M.G., 2012, Effectiveness of common fish screen materials to protect lamprey ammocoetes: North American Journal of Fisheries Management, v. 32, no. 3, p. 597603.

Skalicky, J.J., Harris, J.E., Barkstedt, J.M., Gray, A.E., and Clemens, B.J., 2019, Evaluation of changes in abundance and methods for salvage of larval lamprey during a "slow" water drawdown and dewatering in Leaburg Reservoir, Oregon-FY 2019 final report: Final report prepared by U.S. Fish and Wildlife Service, Columbia River Fish and Wildlife Conservation Office, Vancouver, Washington, 30 p. [Also available at https://www.fws.gov/CRFWCO/CRFPO_pubs.cfm]

Wang, C., and Schaller, H., 2015, Conserving Pacific Lamprey through collaborative efforts: Fisheries, v. 40, no. 2, p. 72-79. 
Publishing support provided by the U.S. Geological Survey Science Publishing Network, Tacoma Publishing Service Center

For more information concerning the research in this report, contact the Director, Western Fisheries Research Center

U.S. Geological Survey 6505 NE 65th Street

Seattle, Washington 98115-5016

https://www.usgs.gov/centers/wfrc 
